\title{
Estimation of soil salt content by combining UAV-borne multispectral sensor and machine learning algorithms
}

\author{
Guangfei Wei ${ }^{1,2}$, Yu Li $^{\text {Corresp., }}{ }^{1}$, Zhitao Zhang ${ }^{\text {Corresp., } 1,2}{ }^{2}$, Yinwen Chen ${ }^{3}$, Junying Chen ${ }^{1,2}{ }^{2}$ Zhihua Yao ${ }^{1,2}$, Congcong Lao \\ 1,2 , Huifang Chen ${ }^{1,2}$ \\ ${ }^{1}$ College of Water Resources and Architectural Engineering, Northwest A \& F University, Yangling, China \\ 2 Key Laboratory of Agricultural Soil and Water Engineering in Arid and Semiarid Areas of Ministry of Education, Northwest A \& F University, Yangling, \\ China \\ 3 Department of Foreign Languages, Northwest A \& F University, Yangling, China \\ Corresponding Authors: Yu Li, Zhitao Zhang \\ Email address: liyu2188@aliyun.com, zhangzhitao@nwafu.edu.cn
}

Soil salinization is a global problem closely related to the sustainable development of social economy. Compared with frequently-used satellite-borne sensors, unmanned aerial vehicles (UAVs) equipped with multispectral sensors provide an opportunity to monitor soil salinization with on-demand high spatial and temporal resolution. This study aims to quantitatively estimate soil salt content (SSC) using UAV-borne multispectral imagery, and explore the deep mining of multispectral data. For this purpose, a total of 60 soil samples $(0 \sim 20 \mathrm{~cm})$ were collected from Shahaoqu Irrigation Area in Inner Mongolia, China.

Meanwhile, from the UAV sensor we obtained the multispectral data, based on which 22 spectral covariates ( 6 spectral bands and 16 spectral indices) were constructed. The sensitive spectral covariates were selected by means of gray relational analysis (GRA), successive projections algorithm (SPA) and variable importance in projection (VIP), and from these selected covariates estimation models were built using back propagation neural network (BPNN) regression, support vector regression (SVR) and random forest (RF) regression, respectively. The performance of the models was assessed by coefficient of determination $\left(R^{2}\right)$, root mean squared error (RMSE) and ratio of performance to deviation (RPD). The results showed that the estimation accuracy of the models had been improved markedly using three variable selection methods, and VIP outperformed GRA and GRA outperformed SPA. However, the model accuracy with the three machine learning algorithms turned out to be significantly different: RF $>$ SVR $>$ BPNN. All the twelve SSC estimation models could be used to quantitatively estimate SSC (RPD $\square 1.4$ ) while the VIPRF model achieved the highest accuracy $\left(R_{c}{ }^{2}=0.835, R_{\mathrm{p}}{ }^{2}=0.812, \mathrm{RPD}=2.299\right)$. The result of this study proved that UAV-borne multispectral sensor is a feasible instrument for SSC estimation, and provided a reference for further similar research. 
1 Estimation of soil salt content by combining

2 UAV-borne multispectral sensor and machine

3 learning algorithms

4

7

9




\section{ABSTRACT}

Soil salinization is a global problem closely related to the sustainable development of social economy. Compared with frequently-used satellite-borne sensors, unmanned aerial vehicles (UAVs) equipped with multispectral sensors provide an opportunity to monitor soil salinization with on-demand high spatial and temporal resolution. This study aims to quantitatively estimate soil salt content (SSC) using UAV-borne multispectral imagery, and explore the deep mining of multispectral data. For this purpose, a total of 60 soil samples $(0 \sim 20 \mathrm{~cm})$ were collected from Shahaoqu Irrigation Area in Inner Mongolia, China. Meanwhile, from the UAV sensor we obtained the multispectral data, based on which 22 spectral covariates (6 spectral bands and 16 spectral indices) were constructed. The sensitive spectral covariates were selected by means of gray relational analysis (GRA), successive projections algorithm (SPA) and variable importance in projection (VIP), and from these selected covariates estimation models were built using back propagation neural network (BPNN) regression, support vector regression (SVR) and random forest (RF) regression, respectively. The performance of the models was assessed by coefficient of determination $\left(R^{2}\right)$, root mean squared error (RMSE) and ratio of performance to deviation (RPD). The results showed that the estimation accuracy of the models had been improved markedly using three variable selection methods, and VIP outperformed GRA and GRA outperformed SPA. However, the model accuracy with the three machine learning algorithms turned out to be significantly different: RF $>$ SVR $>$ BPNN. All the twelve SSC estimation models could be used to quantitatively estimate SSC (RPD>1.4) while the VIP-RF model achieved the highest accuracy $\left(R_{\mathrm{c}}{ }^{2}=0.835, R_{\mathrm{P}}{ }^{2}=0.812, \mathrm{RPD}=2.299\right)$. The result of this study proved that UAV-borne multispectral sensor is a feasible instrument for SSC estimation, and provided a reference for further similar research.

\section{INTRODUCTION}

Soil salinization is a global ecological and environmental problem, which has become one of the main obstacles to agricultural production and sustainable economic development, especially in arid and semi-arid areas (Wu et al., 2008). The process of salinization is mainly due to the comprehensive influence of specific natural conditions (geological, topographic and climatic conditions) and improper agricultural practice. It is reported that salinized soil has a high concentration of salt ions, directly affecting the normal growth, yield and quality of crops (Tavakkoli et al., 2011; Munns, 2010). To manage and utilize saline soil, some effective methods are needed to acquire the saline soil information quickly, dynamically and accurately in arid and semi-arid areas.

Soil salt content (SSC) is an effective evaluation indicator of soil salinization (Gorji et al., 2015). Field-based (in-situ) are logistically difficult such as labor intensive and time-consuming (Metternicht \& Zinck, 2003). Many scholars monitored soil salinization using satellite-borne remote sensing (RS) data together with field 
measurement over last two decades (Yu et al., 2018 ; Allbed et al., 2014 ; Ivushkin et al., 2019), yet satellite images can be easily affected by bad weather and unfavorable revisit times. The recent development of unmanned aerial vehicle (UAV) has ushered in a new era enabling monitoring of environment and agriculture at unprecedented temporal and spatial, especially in the monitoring of such soil ingredients as moisture, heavy metals and organic carbon (Gilliot et al., 2016; Bian et al., 2019; Yi et al., 2018 Easterday et al., 2019; Jay et al., 2018). There have been a few cases involving the application of UAV-borne RS in soil salinization monitoring. For instance, Ivushkin et al. (2019) combined three UAV-borne sensors to measure salt stress in quinoa plants, and their result showed UAV-borne RS was a useful technique to measure salt stress in plants. $\mathrm{Hu}$ et al. (2019) characterized and estimated soil salinity using a hyperspectral and electromagnetic induction (EMI) equipment mounted on a UAV platform, and concluded that UAV-borne hyperspectral imager was an effective tool for field-scale soil salinity monitoring and mapping. Aside from these studies, existing research showed that the majority of UAV-borne soil salinity estimations were conducted using hyperspectral or thermal cameras while there are few reports on the application of UAV-borne multispectral imagery to soil salt estimations. Compared with hyperspectral sensors, multispectral sensors have a much lower cost, and the band preprocessing is relatively simple, so it is significative to assess the capability of UAV-borne multispectral sensor in SSC estimation.

The spectral index, a composition of different spectral wavebands, has been frequently used to establish the correlation between spectral data and the information of soil salinization (Allbed et al., 2014; Allbed et al., 2014). A series of common salt indices, including Normalized Difference Salinity Index (NDSI) (Zewdu et al., 2017), Salinity Index (SI) (Allbed et al., 2014) and Simple ratio index (SR) (Chen, 1996), have been widely used to represent soil salinization. Besides, some two-band (2D) indices and three-band indices (TBI) were proposed for the estimation of soil moisture content and soil electric conductivity, and the results showed that these newly proposed indices containing more spectral information displayed a higher correlation with measured data (Wang et al. 2019).

However, such indices construction will generate a large amount of redundant information, so it is important to filter the redundant information through variable selection method for model optimization. Research has shown that variable selection methods can improve the model predictive accuracy (Hong et al., 2018). Variable importance in projection (VIP) scores evaluates the importance of each variable in the projection used in a PLS model. Gray relational analysis (GRA) identify the primary and secondary relations among variables through the calculation and comparison of correlation sequence, and they both have been proved to be effective methods for variable selection (Santos, 2019; Wang et al., 2018). Successive projections algorithm (SPA) is a variable selection method widely used in food and chemical engineering (Diniz et al., 2015; Ghasemi-Varnamkhasti et al., 2012; Wu et al., 2009). Wang et al. (2019) proved the applicability of SPA method to soil salinity estimation, and the 
114 SPA method improved the accuracy of the inversion model. However, there are few

\section{5} studies on the application of these three variable selection methods to SSC estimation.

A common method to estimate SSC is the utilization of the mathematical statistical model using RS data, especially the linear regression model including partial least squares regression (PLSR) (Farifteh et al., 2007; Xu \& Wang, 2015; Sidike et al., 2014). But the relationship between spectral covariates and soil properties is rarely linear in nature (Ge et al., 2019). Machine learning provides an alternative mean of fitting nonlinear problems (Nawar et al., 2016). Machine learning algorithms, including back propagation neural network (BPNN), support vector regression (SVR), random forest (RF), extreme learning machine (ELM) and Cubist, have been extensively used in the quantitative estimation recently (Hoa et al., 2019; Shataee et al., 2012; Maimaitiyiming et al., 2019; Li et al., 2015; Houborg \&Mccabe, 2018). The BPNN algorithm, strong in nonlinear fitting and self-learning, has been proven to be superior to traditional linear regression in prediction accuracy in many studies (Pradhan\&Lee, 2010; Bansal et al., 2011). The SVR algorithm grounded on kernel-based learning methods has the ability to solve nonlinear and high-dimensional problems. Chen et al. (2015) reported that SVR algorithm could effectively improve the accuracy of SSC estimation using the modified vegetation index. Many scholars have concluded that the RF algorithm has such unique advantages as small sample data processing, and nonlinear fitting problem solving (Mutanga et al., 2012; Oliveira et al., 2012). For instance, Cushman \& Wasserman (2018) compared logistic regression and RF in multi-scale predictive model, and concluded the RF model had a much stronger ability to estimate presences and absences in the training set than logistic regression model. These studies showed that BPNN, SVR and RF are feasible methods for quantitative estimation. However, most of the existing researches focused on the comparison between machine learning algorithms and linear regression methods, and there is a lack of the combination of these three machine learning methods.

So far there are many researches on hyperspectral data mining (Wang et al., 2019), but very few reports on deep mining of UAV-borne multispectral data. We try to answer the following questions: the correlation between spectral indexes and SSC tends to vary, so which spectral indexes are suitable for this study and which variable selection method is the most effective? Which selection method and which regression algorithm can be combined to have the best prediction accuracy? These questions are unavoidable in UAV-borne multispectral monitoring of soil salinity.

Specifically, this study aimed to: (1) evaluate the potential and feasibility of UAV-borne multispectral RS for SSC quantitative estimation; (2) compare the effect of GRA, SPA and VIP on model accuracy, and investigate whether the three variable selection methods can improve the model predictive accuracy; (3) compare the prediction accuracy of BPNN, SVR and RF models, and identify the optimal SSC quantitative estimation model.

\footnotetext{
Peer) reviewing PDF | (2019:10:42629:2:1:CHECK 1 Apr 2020)
} 


\section{Study Area}

157 Hetao Irrigation District (HID) is one of the three major irrigated areas in China. It is

158 located in the upstream of the Yellow River and the west of Inner Mongolia. With a

159 total irrigation area of $5740 \mathrm{~km}^{2}$, HID is an important production base of cereal and 160 oil plants in China. Shahaoqu Irrigation Area $\left(107^{\circ} 05^{\prime} \sim 107^{\circ} 10^{\prime} \mathrm{E}, 40^{\circ} 52^{\prime} \sim 41^{\circ} 00^{\prime} \mathrm{N}\right)$,

161 a typical region of saline soil in HID, was chosen as the study area (Figure 1). Its

162 terrain surface is relatively flat with the altitude from $1034 \mathrm{~m}$ to $1037 \mathrm{~m}$. The climate

163 is typically temperate continental, with its mean precipitation, evaporation and annual

164 temperature of about $140 \mathrm{~mm}, 2000 \mathrm{~mm}$ and $7{ }^{\circ} \mathrm{C}$, respectively, and the frost-free period of $120 \sim 150$ days. The local soil texture is mainly silty clay loam. Due to the unreasonable high irrigation, low drainage of local agriculture and the impact of such natural factors as geological, topographic and climatic conditions, the problem of salinization in this area is increasingly prominent, seriously affecting the development of local agricultural economy (Wu et al., 2008; Gao et al., 2015).

\section{Data Collection}

\section{Sample Collection and Chemical Analysis}

172 The Hetao irrigation district administration gave field permit approval to us

173 (NO.2017YFC0403302). Considering the various degree of salinization in Shahaoqu 174 Irrigation Area, We chose four typical and representative areas (Area A, B, C and D, 175 in Figure 1) with different degrees of salinization in the farmland. Fifteen sampling 176 cells $(0.5 \mathrm{~m} \times 0.5 \mathrm{~m})$ of bare soil were distributed in each area $\left(16 \mathrm{hm}^{2}\right)$. Altogether 60 177 sampling cells were identified, and the geographical position of each cell was 178 recorded by GPS (Figure 2). Samples were collected from May 14 to May 17, 2018, 179 with a sampling depth of 0 to $20 \mathrm{~cm}$. The soil samples were stored and sealed in 180 aluminum boxes.

181 All the soil samples were dried, ground, and then passed through a $2.0 \mathrm{~mm}$ sieve 182 to wipe off small stones and deadwood in the laboratory. Subsequently, the soil 183 solution was prepared with the soil to water ratio of 1:5. After 8 hours of full 184 immersion, the electrical conductivity $\left(\mathrm{EC}_{1: 5}, \mathrm{ds} / \mathrm{cm}\right)$ of the soil solution was 185 measured by conductivity meter (DDS-307A, Shanghai Youke Instrument Branch, 186 China), and then the SSC (\%) was calculated by empirical formula: SSC $=(0.2882$ $187 \quad \mathrm{EC}_{1: 5}+0.0183$ ) (Huang et al., 2018).

\section{Acquisition and Processing of UAV-borne Multispectral Data}

189 The flight platform adopted was the DJI Matrice 600 six-rotor UAV (Shenzhen 190 Dajiang Innovation Technology Co., Ltd., China) equipped with a Micro-MCA 191 multispectral sensor (Tetracam Corporation, USA) (Figure 3).The sensor is light, 192 small and remote controllable. The parameters of the sensor are shown in Table 1. 193 Simultaneous with the collection of soil samples, the UAV RS imagery of the four 194 areas were acquired at 13:00 Beijing time every day from May 14 to May 17, 2018. 195 The weather was sunny and windless, which is favorable for data acquisition. The 196 UAV followed the fixed route at a height of $120 \mathrm{~m}$, the spatial resolution of the 
197 imagery being $6.5 \mathrm{~cm}$. The images were captured every 3 seconds and its overlap rate was $85 \%$.

The post-processing of images included image mosaicking, geometric correction, radiation correction and orthographic correction with software Pix4D mapper 2.0.104 (Lausanne, Switzerland). Then four false color composite band images were generated and the sampling points of GPS information were input into the four images of the study area via software ENVI Classic. The gray values of the six bands of each sampling point and the whiteboard were extracted and the reflectance of the sampling points was obtained from the division of the former by the latter.

\section{Spectral Indices Construction}

The spectral index is highly related to soil surface, which is an effective indictor to monitor soil salinization. Therefore, some of widely used soil salinity indices were chosen in this study. In addition, to find the sensitive spectral indices suitable for the study area and fully dig for the spectral data information, we built three 2D indices: the difference index (DI), the ratio index (RI) and the normalization index (NDI). The formulas of the spectral indices above are shown in Table 2.

\section{Variable Selection Methods}

\section{Gray Relational Analysis}

GRA is an approach to measure the degree of correlation between factors according to the degree of similarity or difference in the development trend between factors. Its basic principle is to identify the primary and secondary relations among various factors through the calculation and comparison of correlation degrees (Wang et al. 2018).GRA requires less data, and the principle is simple to grasp. The calculation steps of this method are: (1) determining comparison sequence and reference sequence; (2) normalizing the spectral data; (3) calculating correlation coefficient; and (4) calculating correlation degree and ranking gray correlation degree (GCD). The calculation process is completed by software DPS 7.05 which is a data processing system made in China. The formula of GCD is:

$G C D=\frac{1}{n} \sum_{i=1}^{n} \gamma\left(x_{0}(k), x_{i}(k)\right)$

where $\gamma\left(x_{0}(k), x_{i}(k)\right)=\frac{\min _{i} \max _{k}\left|x_{0}(k)-x_{i}(k)\right|+\rho \min _{i} \max _{k}\left|x_{0}(k)-x_{i}(k)\right|}{\left|x_{0}(k)-x_{i}(k)\right|+\rho \min _{i} \max _{k}\left|x_{0}(k)-x_{i}(k)\right|}$,

$\rho$ is the distinguishing coefficient with a value range[0,1]. In this study, $\rho$ was set as 0.5 .

\section{Successive Projections Algorithm}

SPA is a forward variable selection algorithm that minimizes collinearity in vector space, which uses a simple projection operation in vector space to obtain minimum co-linear variable subset. And it can greatly eliminate the co-linear effect between independent variables, thereby reducing the model complexity and improving the Peer) reviewing PDF | (2019:10:42629:2:1:CHECK 1 Apr 2020) 
$P x_{j}=x_{j}-\left(x_{j}^{T} x_{k(n-1)}\right) x_{k(n-1)}\left(x_{j}^{T} x_{k(n-1)}\right)^{-1}$

where $P$ is the projection operator; all $j \in S, S$ represents the set of unselected variables; $K$ represents the selected independent variables.

\section{Variable Importance in Projection}

VIP is a variable selection method based on PLSR which was first proposed by Wold et al. (1983). VIP scores offer a useful method to select the variables which contribute the most to the Y's variance explanation. And it is calculated as follows:

$$
V I P=\sqrt{k \times \frac{\sum_{a=1}^{A} R_{d}(Y, t) W^{2}}{\sum_{a=1}^{A} R_{d}(Y, t)}}
$$

where $K$ represents the total number of independent variables; $A$ is the number of components; $\mathrm{t}$ represents the selected independent variables; $R_{d}(Y, t)$ represents the interpretation degree of components to dependent variables; $W^{2}$ represents the importance of variable in each component; the value of VIP $>1$ indicates a strong relation between independent variables and dependent variables.

\section{Model Construction and Validation}

In this study, three machine learning algorithms, including BPNN, SVR and RF, were applied to the quantitative inversion of SSC. The main method process is shown in Figure 4.To ensure that calibration dataset and validation dataset can represent the statistical characteristics of the entire dataset, the division of samples was based on the Kennard-Stone (k-s) algorithm (Kennard\&Stone, 1969), and 40 samples were selected as the calibration dataset and 20 samples as the validation dataset.

BPNN is a multi-layer feedforward neural network trained according to the error back propagation algorithm. It does not need to establish a specific mathematical model in data analysis, and has strong fitting ability to figure out multi-factor nonlinear problems. The BPNN model topology includes the input layer, the hidden layer, and the output layer (Wang et al. 2018). The sensitive variables selected by the three variable selection methods were input layers in this study, the measured SSC data were the output layer, and the size of hidden layer nodes was determined by cross-validation.

SVR is a machine learning algorithm based on the principle of structural risk minimization. It has the advantages of simple structure, strong adaptability, and powerful capability of tackling small sample, nonlinear and high-dimensional data problems (Wang et al. 2019). In this study, the kernel function was set as polynomial kernel function (Polynomial). The training set cross-validation and grid search were used to optimize the parameters. The penalty parameter $(C)$ and the nuclear parameter $(g)$ were determined by a grid-searching technique and a leave-one-out cross validation procedure.

$\mathrm{RF}$ is an integrated learning algorithm of bagging algorithm and decision tree algorithm, which can fit the complex nonlinear relationship between independent variables and dependent variables (Wang et al. 2019). The major parameters in this 
274 algorithm were set as follows: the scale was set as "TRUE", and the number of trees

275 (ntree) was set as 500, the number of features tried at each node (mtry) depends on the

276 lowest out-of-bag error. The above three machine learning algorithms were conducted

277 via software R3.5.1 using the packages of "nnet", "e1071" and "randomForest"

278 respectively.

279 The accuracy of the model was evaluated using coefficient of determination $\left(R^{2}\right)$, 280 root mean squared error (RMSE) and ratio of performance to deviation (RPD). Model 281 prediction accuracy can be divided into three levels: Level A (RPD>2.0) indicates 282 very good model prediction; Level $\mathrm{B}(1.40 \leqslant \mathrm{RPD} \leqslant 2.00)$ rough quantitative 283 estimation; Level C (RPD < 1.40) unreliable model prediction (Chang et al., 2001). A reliable model usually has the characteristics of high $R^{2}$ and RPD values and low RMSE value. All the three evaluation indicators were calculated via software R3.5.1.

\section{RESULTS}

\section{Chemical Characteristics}

With reference to the classification standard for soil salinization degree (Huang et al. 2018), the summary statistics are shown in Table 3. The proportion of none salinized soil, mild salinized soil and severe salinized soil in the total samples is $33 \%, 40 \%$, and $27 \%$, respectively, which is basically consistent with our field investigation. The coefficient of variation (CV) of the total sample was $54 \%$, that is, the variability of soil salinity was not obvious in the cultivated area of the irrigation area.

The statistics of SSC for the entire dataset, calibration dataset and validation dataset are shown in Figure 5. The statistical indicators of the entire dataset were close to that of the calibration dataset and the validation dataset, indicating that the SSC of the two selected datasets represented the entire dataset. Compared with the field survey results, the degree of the salinization at the sampling points can truly represent that of the cultivated land in the irrigated areas.

\section{The relationship between SSC and spectral indices}

Table 4 shows the relationships between the spectral indices and SSC. Correlation analysis showed a significant positive correlation $(\mathrm{p}<0.01)$ between SSC and S1, S3, S4, S5, S6-1, BI-1 and NDSI-2, and a significant positive correlation $(p<0.05)$ between SSC and S2, S6-2, SR-2. The correlation coefficients of the measured SSC data and the three 2D indices (RI, DI and NDI) for the two random spectral bands selected in multispectral bands are shown in Figure 6.

The bands with higher correlation between SSC and RI, DI, NDI, respectively, were mainly concentrated on the red-edge band (B4) and two near infrared bands (B5, B6). Then each $2 \mathrm{D}$ index with the optimal band combinations in the three were applied to subsequent variable selection, and their correlation coefficients with SSC were calculated. The maximal absolute values of PCC between SSC and RI, DI, NDI, were $0.59,0.49$ and 0.55 , respectively. 


\section{Selection of Sensitive Variables}

314 The GRA of the twenty-two spectral covariates (six spectral bands, thirteen soil

315 salinity indices and three 2D indices) and measured SSC were conducted by the gray

316 system in the software DPS, and the result is shown in Figure 7. For the purpose of

317 variable selection, the GCD threshold of sensitive variables was set as 0.7 , and seven

318 variables, including B4, B6, S1, S6-2, SR-1, SR-2 and RI, were finally identified as

319 sensitive variables.

320 The sensitive variables were selected by SPA method via MATLAB R2014b

321 (Figure 8) (Araújo et al., 2001; Galvão et al., 2001). The selected variables were B3

322 and NDSI, accounting for only $9 \%$ of the total number of variables, so the complexity

323 of the model was greatly reduced.

324 The VIP score of each variable was calculated using MATLAB R2014b (Figure

325 9). Then variables with scores higher than 1 were selected, namely, NDSI-2, S1, SR-1, 326 SR-2, BI-1, BI-2, and RI.

\section{Model Estimations and Comparisons}

328 Based on the selection criteria in the previous section, seven sensitive variables (B4, B6, S1, S6-2, SR-1, SR-2 and RI) were selected using GRA; B3 and NDSI-1 were selected using SPA; seven variables (NDSI-2, S1, SR-1, SR-2, BI-1, BI-2, and RI) were selected using VIP. Based on all the variables and the above sensitive variables, three machine learning models (BPNN, SVR and RF) were conducted to estimate SSC. The model parameters are shown in Table 5 and the results are shown in Table 3346 .

\section{Analysis of BPNN Model}

336 First of all, from the results of the calibration, the $R_{\mathrm{c}}{ }^{2}$ of the three variable selection methods were close to each other and all bigger than 0.64, and their RMSE $\mathrm{C}_{\mathrm{C}}$ were all below 0.12 . The comparison among the $R_{\mathrm{P}}{ }^{2} 、 \mathrm{RMSE}_{\mathrm{P}}$ and RPD indicated that VIP had the highest prediction accuracy, GRA came next, and the SPA the lowest. The RPD of the three selection models were between 1.6 and 1.8, while the estimation performance of Raw-BPNN model showed the lowest values $(\mathrm{RPD}=1.494)$. With reference to the three-level classification of RPD, BPNN models could only roughly

343 estimate SSC quantitatively.

\section{Analysis of SVR Model}

345 In terms of calibration effect, the accuracy of the VIP and GRA were relatively close, 346 and both $R_{\mathrm{c}}{ }^{2}$ were bigger than 0.64 . The SPA did not show strong fitting effect, with 347 the lowest $R_{\mathrm{c}}{ }^{2}(0.581)$ and highest $\operatorname{RMSE}_{\mathrm{C}}(0.126)$. The validation results were similar 348 to the calibration results, and the VIP was only slightly higher than the GRA in 349 prediction accuracy while the SPA had the worst. Raw-SVR model had the worst 350 performance. In summary, the $R_{\mathrm{P}}{ }^{2} / R_{\mathrm{c}}{ }^{2}$ of the SVR models based on the three variable 351 selection methods were all close to 1, indicating that the SVR models had good 352 robustness (Wang et al. 2018).

\section{Analysis of RF Model}


354 Raw-RF model had the lowest accuracy among the four RF models. According to the

355 accuracy of comprehensive calibration and validation, all the three selection RF models achieved good effects $\left(R_{\mathrm{c}}{ }^{2}>0.7\right)$ and the RPD reached up to $1.949,1.895$, and 2.299 , respectively. The respective $R_{\mathrm{P}}{ }^{2} / R_{\mathrm{c}}{ }^{2}$ of the three selection models were 0.9961 , 0.9853 and 0.9725 , indicating that there was neither over-fitting nor under-fitting. Therefore, it can be concluded that the RF algorithm had excellent robustness and predictive ability.

\section{Comprehensive Evaluation and Analysis of the Model}

Figure 9 shows the performance of the validation models. The estimation accuracy of the models was improved in varying degrees using three variable selection methods, and the values of $R_{\mathrm{P}}{ }^{2}$ were improved by 0.1 or more. It is interesting that the choice of the different variable selection methods had less difference on model precision. The mean value of RPD of VIP, GRA, and SPA were 1.758, 1.726, and 1.903, respectively. It can be seen from Figure 10 that the performance of the three selected methods is VIP $>$ GRA $>$ SPA while the mean value of the RPD is not obviously different.

On the premise of the same variable selection method, different machine learning algorithms demonstrated significant differences in the model prediction accuracy. The mean value of the RPD of RF, BPNN and SVR were 2.048, 1.755 and 1.566, respectively. Three RF models displayed high prediction accuracy, while the BPNN models under-fitting and SVR models low prediction accuracy.

Figure 11 shows a comparison between the estimation results of the nine variable selection models and the measured values. The RPD values of all the nine models were bigger than 1.4, suggesting that all models had the ability to quantitatively estimate SSC. The VIP-RF was the model with the best prediction performance $(\mathrm{RPD}=2.299)$, and its validation dataset points were well distributed on both sides of $1: 1$ line. In addition, the selection of model regression method has a greater impact than that of the variable selection method on the prediction accuracy of SSC.

\section{DISCUSSION}

The UAV-borne multispectral RS technique has a great application potential for SSC estimation. Compared with field sampling, UAV cost much lower. Establishing an effective SSC estimation model is of great significance for salinization monitoring in arid and semi-arid areas. Usually, a large number of spectral covariates will be generated in the process of the estimation model construction, but these covariates may contain redundant information, so the selection of sensitive variables is a key step in building an optimal model. In this study, among the twenty-two spectral covariates the ones with higher weights were NDSI, B3 and SR according to the results of the three selection methods. The bands of the three variables were mainly at red band $(680 \mathrm{~nm})$ and two near-infrared bands $(800 \mathrm{~nm}, 900 \mathrm{~nm})$, which is consistent with the results of former researches (Wang et al., 2019; Chen, 2018). The main 
394 water-soluble ions of our study area are $\mathrm{Na}^{+}, \mathrm{Ca}^{2+}, \mathrm{Cl}^{-}$and $\mathrm{SO}_{4}{ }^{2-}$ (Wang et al., 2019).

395 The visible-near infrared reflectance of salinized soil is higher than that of non-salinized soil (Weng et al., 2006). (Chen, 2018) proposed that salinized soil had an absorption peak at $671 \mathrm{~nm}$, and (Wang et al., 2019) found that the sensitive band of SSC was at $882 \mathrm{~nm} \sim 997 \mathrm{~nm}$. These studies revealed that the three bands $(680 \mathrm{~nm}$, $800 \mathrm{~nm}$ and $900 \mathrm{~nm}$ ) contained more information related to soil salinity.

In this research, the number of variables selected by the three methods was 7, 7,

401

402

403

404

405

406

407

408

409

410

411

412

413

414

415

416

417

418

419

420

421

422

423

424

425

426

427

428

429

430

431

432

433

434

435 and 2, respectively, which effectively simplified the estimation model and improved the modeling efficiency. The application of three variable selection methods did improve the accuracy of the estimation models markedly. From the model prediction accuracy, the three selection methods ranked from high to low were: VIP, GRA, and SPA, and this result were consistent with that of Wang et al. (Wang et al. 2019). The SPA method had the lowest accuracy, the possible reason for this result is that the method only selected two variables (9\%) and missed some relevant spectral information possibly. However, there was no significant accuracy difference using three different variable selection methods, which may be due to the fact that the number of spectral variables set in this study was not large and these methods were mostly used for hyperspectral wavelength selection. We suppose that the selection of regression model method has a more significant impact on the prediction accuracy than that of variable selection method in that the multispectral estimation model has relatively little spectral information.

All of the estimation models achieved satisfactory results (RPD $>1.4$ ), and $R_{\mathrm{P}}{ }^{2} /$ $R_{\mathrm{c}}{ }^{2}$ were close to 1 , that is, there was no over-fitting in the prediction results, which indicates that the machine learning algorithm can well fit the complex nonlinear relationship (Nawar et al., 2016). The RPD based on the three RF models were 1.949, 1.895 and 2.299, respectively. Different machine learning algorithms had different results, and the RF algorithm demonstrated the best performance. Many scholars drew similar conclusions when comparing regression methods in the estimation models (Douglas et al., 2018; Zeraatpisheh et al., 2019; Antoine et al., 2013). For example, Gomes et al. (2019) established the predicting models of soil organic carbon content using RF, SVR, Cubist and Generalized Linear Models (GLM) and the result showed that the RF algorithm achieved the best prediction result. Ge et al. (2019) estimated soil moisture by combining UAV-based hyperspectral imagery and two machine learning algorithms, and concluded the RF models were superior to the ELM models. These researches have demonstrated that RF is an outstanding and stable ensemble-learning algorithm to construct estimation models that can overcome non-linear small sample size, and it has the strong ability to resist overfitting (Lindner et al., 2015; Chen\&Liu, 2005). We think that BPNN and SVR are not necessarily inappropriate algorithms because the prediction results obtained by them are acceptable. SVR belongs to the supervised learning model, and the relative low prediction accuracy of SVR may be due to the fact that SVR models are prone to deviation estimation caused by high noise (Li et al., 2019). Besides, SVR model 
436 turning can be very tricky and getting the parameters right is difficult. BPNN belongs 437 to neural work model, it is tough to fit, and in our three BPNN models, $R_{\mathrm{P}}{ }^{2}$ is slightly 438 larger than $R_{\mathrm{c}}{ }^{2}$, that is, a weak under-fitting phenomenon occurs, which may be the relative small number of verification samples that increased the instability of the prediction results. An effective optimization may occur if the sample size was appropriate.

UAV-borne multispectral RS has the advantages of high resolution and dynamic continuous monitoring. Besides, existing RS data provides a large number of potential resources available, satellite-borne RS data is easy to obtain and covers a large area, portable analytical spectral devices (ASD) provide hundreds of spectral bands. Therefore, we can combine them in the future application, so as to take the particular advantages of multi-source RS data, and form a multi-scale dynamic continuous SSC monitoring network based on the mathematical estimation model.

Few limitations along with questions for future study should be noted in this research. This paper clearly demonstrated that UAV-borne multispectral RS is an effective tool to estimate SSC. It is well known that soil moisture affects the spectral reflectance, and the existence of such difference will be considered in the subsequent studies. The research was conducted during the short bare soil period in May. It is generally considered that it is more meaningful to estimate the SSC during the crop growth period for the development of precision agriculture. Further researches can focus on establishing SSC model via spectral information of the crop canopy. In addition, estimating SSC by combining machine learning algorithms with RS at different scales will be a future direction.

\section{CONCLUSION}

In this study, we built twelve estimation models of SSC on the basis of UAV-borne multispectral data during the bare soil period in the cultivated area. We finally came to the following conclusions.

Firstly, the RPD values of all models were greater than 1.4, indicating all models have an ability to quantitatively estimate SSC, so UAV-borne multispectral remote sensing is feasible for quantitative SSC estimation.

Secondly, the performance of the models has been improved markedly using the three variable selection methods, and the accuracy varied among the three methods: VIP $>$ GRA $>$ SPA, but this difference was not significant.

Thirdly, the choice of different machine learning algorithms had a great effect on the prediction accuracy of the model. In general, the RF had the highest prediction accuracy and strongest robustness, the SVR followed, and the BPNN had the lowest. The VIP-RF model performed the best among the twelve models with $R_{\mathrm{P}}{ }^{2}, \mathrm{RMSE}_{\mathrm{P}}$ and RPD of $0.812,0.089$ and 2.229, respectively.

The UAV-borne multispectral RS has great potential for SSC estimation in the future. This instrument can present an efficient method to decision makers of agriculture and environment management departments. 


\section{ACKNOWLEDGMENTS}

The authors would like to thank the Key Laboratory of Agricultural Soil and Water Engineering in Arid and Semiarid Areas of Ministry of Education and the Institude of Water Saving Agriculture in Arid Areas of China. The authors want thank Xintao Wang and Jia Han for their enthusiastic help in the process of the paper writing. Conflicts of Interest: The authors declare no conflict of interest.

\section{REFERENCES}

Allbed A, Kumar L, Aldakheel YY.2014. Assessing soil salinity using soil salinity and vegetation indices derived from IKONOS high-spatial resolution imageries: Applications in a date palm dominated region. Geoderma 230-231:1-8.

DOI 10.1016/j.geoderma.2014.03.025

Allbed A, Kumar L, Sinha P. 2014. Mapping and Modelling Spatial Variation in Soil Salinity in the Al Hassa Oasis Based on Remote Sensing Indicators and Regression Techniques. Remote Sensing 6(2): 1137-1157.

DOI 10.3390/rs6021137

Antoine S, Marco N, Gergely T, Luca M, Bas VW, Yh CH. 2013. Prediction of soil organic carbon at the european scale by visible and near infrared reflectance spectroscopy. PLoS ONE 8(6): e66409.

DOI 10.1371/journal.pone.0066409

Araújo MCU, Saldanha TCB, Galvão RKH, Yoneyama T, Chame HC, Visani V. 2001. The successive projections algorithm for variable selection in spectroscopic multicomponent analysis. Chemometrics \& Intelligent Laboratory Systems. 57:65-73.

DOI 10.1016/S0169-7439(01)00119-8

Bansal A, Chen TT, Zhong S. 2011. Privacy preserving Back-propagation neural network learning over arbitrarily partitioned data. Neural Computing \& Applications 20(1):143-150.

DOI 10.1007/s00521-010-0346-Z

Bian J, Zhang ZT, Chen JY, Chen HY, Cui CF, Li XW, Chen SB, Fu QP. 2019. Simplified Evaluation of Cotton Water Stress Using High Resolution Unmanned Aerial Vehicle Thermal Imagery. Remote Sensing. 11(3): 267.

DOI 10.3390/rs11030267

Chang C-W, Lair DA, Mausbach MJ, Hurburgh CR. 2001. Near infrared reflectance spectroscopy-Principal components regression analyses of soil properties. Soil Science Society of America Journal 65(2): 480-490

DOI 10.2136/sssaj2001.652480x

Chen HY, Zhao GX, Chen JC, Wang RY, Gao MX. 2015. Remote sensing inversion of saline soil salinity based on modified vegetation index in estuary area of Yellow River. Transactions of the Chinese Society of Agricultural Engineering .31(5):107-114.

DOI 10.3969/j.issn.1002-6819.2015.05.016 
Chen JM. 1996. Evaluation of Vegetation Indices and a Modified Simple Ratio for Boreal Applications. Canadian Journal of Remote Sensing 22(3):229-242.

DOI 10.1080/07038992.1996.10855178

Chen MJ. 1996. Evaluation of Vegetation Indices and a Modified Simple Ratio for Boreal Applications. Canadian Journal of Remote Sensing 22:229-242.

DOI 10.1080/07038992.1996.10855178

Chen WJ. 2018. Soil salinity retrieval and dynamic analysis based on spectral intercalibration of Multi-Sensor data. Master's Thesis, Southeast University, China.

Chen XW, Liu M. 2005. Prediction of protein-protein interactions using random decision forest framework. Bioinformatics 21:4394-4400.

DOI 10.1109/TMECH.2002.806232

Cushman SA, Wasserman TN. 2018. Landscape Applications of Machine Learning: Comparing Random Forests and Logistic Regression in Multi-Scale Optimized Predictive Modeling of American Marten Occurrence in Northern Idaho, USA. Machine Learning for Ecology and Sustainable Natural Resource Management 185-203.

DOI 10.1007/978-3-319-96978-7_9

Diniz PHGD, Pistonesi MF, Alvarez MB, Band BSF, Araújo MCUD. 2015. Simplified tea classification based on a reduced chemical composition profile via successive projections algorithm linear discriminant analysis (SPA-LDA). Journal of Food Composition and Analysis 39:103-110.

DOI 10.1016/j.jfca.2014.11.012

Douglas RK, Nawar S, Alamar MC, Mouazen AM, Coulon F. 2018. Rapid prediction of total petroleum hydrocarbons concentration in contaminated soil using vis-NIR spectroscopy and regression techniques. Science of Total Environment 616-617:147-155.

DOI 10.1016/j.scitotenv.2017.10.323

Easterday K, Kislik C, Dawson TE, Hogan S, Kelly M. 2019. Remotely Sensed Water Limitation in Vegetation: Insights from an Experiment with Unmanned Aerial Vehicles (UAVs). Remote Sensing 11: 1853.

DOI 10.3390/rs11161853

Farifteh J, Van der Meer F, Atzberger C, Carranza EJM. 2007. Quantitative analysis of salt-affected soil reflectance spectra: A comparison of two adaptive methods (PLSR and ANN). Remote Sensing of Environment 110: 59-78.

DOI 10.1016/j.rse.2007.02.005

Galvão RKH, Pimentel MF, Araujo MCU, Yoneyama T, Visani V. 2001. Aspects of the successive projections algorithm for variable selection in multivariate calibration applied to plasma emission spectrometry. Analytica Chimica Acta 443(1): 107-115.

DOI 10.1016/S0003-2670(01)01182-5

Gao X, Huo Z, Bai Y, Feng S, Huang G, Shi H, Qu Z. 2015. Soil salt and groundwater change in flood irrigation field and uncultivated land: a case study based on 4-year field observations. Environmental Earth Sciences 73:2127- 
563

564

565

566

567

568

569

570

571

572

573

574

575

576

577

578

579

580

581

582

583

584

585

586

587

588

589

590

591

592

593

594

595

596

597

598

599

600

601

602

603

604

605

606

2139.

DOI 10.1007/s12665-014-3563-4.

Ge XY, Wang JZ, Ding JL, Cao XY, Zhang ZP, Liu J, Li XH. 2019. Combining UAV-based hyperspectral imagery and machine learning algorithms for soil moisture content monitoring. PeerJ. 7:e6926.

DOI $10.7717 /$ peerj. 6926

Ghasemi-Varnamkhasti M, Mohtasebi SS, Rodriguez-Mendez ML, Gomes AA, Araújo MCU, Galvao RK H. 2012. Screening analysis of beer ageing using near infrared spectroscopy and the Successive Projections Algorithm for variable selection. Talanta. 89(2):86-291.

DOI 10.1016/j.talanta.2011.12.030

Gilliot JM, Vaudour E, Joël M. 2016. Mapping within-field variations of soil organic carbon content using UAV multispectral visible near-infrared images. Egu General Assembly Conference. EGU General Assembly Conference Abstracts, Thiverval-Grignon, France.

Gomes LC, Faria RM, Souza ED, Veloso GV, Schaefer CEGR, Filho EIF. 2019. Modelling and mapping soil organic carbon stocks in Brazil. Geoderma 340:337-350.

DOI 10.1016/j.geoderma.2019.01.007

Gorji T, Tanik A, Sertel E. 2015. Soil Salinity Prediction, Monitoring and Mapping Using Modern Technologies. Procedia Earth and Planetary Science 15:507-512.

DOI 10.1016/j.proeps.2015.08.062

Hoa PV, Giang NV, Binh NA, Hai LVH, Pham TD, Hasanlou M, Bui DT. 2019. Soil Salinity Mapping Using SAR Sentinel-1 Data and Advanced Machine Learning Algorithms: A Case Study at Ben Tre Province of the Mekong River Delta (Vietnam). Remote Sensing 11(2):128.

DOI 10.3390/rs11020128

Hong YS, Chen YY, Yu L, Liu YF, Liu YL, Zhang Y, Liu Y, Cheng H. 2018. Combining Fractional Order Derivative and Spectral Variable Selection for Organic Matter Estimation of Homogeneous Soil Samples by VIS - NIR Spectroscopy. Remote Sensing 10(3): 0479.

DOI $10.3390 /$ rs 10030479

Houborg R, Mccabe MF. 2018. A hybrid training approach for leaf area index estimation via Cubist and random forests machine-learning. ISPRS Journal of Photogrammetry and Remote Sensing, 135:173-188.

DOI 10.1016/j.isprsjprs.2017.10.004

Hu J, Peng J, Zhou Y, Xu DY, Zhao RY, Jiang QS, Fu TT, Wang F, Shi Z. 2019. Quantitative Estimation of Soil Salinity Using UAV-Borne Hyperspectral and Satellite Multispectral Images. Remote Sensing 11(7):736.

DOI 10.3390/rs11070736

Huang QZ, Xu X, Lu LJ, Ren DY, Ke JD, Xiong YW, Huo ZL, Huang GH. 2018. Soil salinity distribution based on remote sensing and its effect on crop growth in Hetao Irrigation District. Transactions of the Chinese Society of Agricultural 
$607 \quad$ Engineering 102-109. (in Chinese).

608 DOI 10.11975/j.issn.1002-6819.2018.01.014

609

610

611

612

613

614

615

616

617

618

619

620

621

622

623

624

625

626

627

628

629

630

631

632

633

634

635

636

637

638

639

640

641

642

643

644

645

646

647

648

649

650

Ivushkin K, Bartholomeus H, Bregt AK, Pulatov A, Franceschini MHD, Kramer H, Loo ENV, Roman VJ, Finkers R. 2019. UAV based soil salinity assessment of cropland. Geoderma 338:502-512.

DOI 10.1016/j.geoderma.2018.09.046

Ivushkin K, Bartholomeus H, Bregt AK, Pulatov A, Kempen B, Sousa LD. 2019. Global mapping of soil salinity change. Remote Sensing of Environment 231: 111260 .

DOI 10.1016/j.rse.2019.111260

Jay S, Frédéric B, Dutartre D, Malatesta G, Héno S, Comar A, Weiss M, Maupas F. 2018. Exploiting the centimeter resolution of UAV multispectral imagery to improve remote-sensing estimates of canopy structure and biochemistry in sugar beet crops. Remote Sensing of Environment 231:110898

DOI 10.1016/j.rse.2018.09.011

Kennard RW, Stone LA. 1969. Computer Aided Design of Experiments. Technometrics. 11(1):137-148.

DOI 10.1080/00401706.1969.10490666

Khan NM, Rastoskuev VV, Sato Y, Shiozawa S. 2005. Assessment of hydrosaline land degradation by using a simple approach of remote sensing indicators. Agricultural Water Management 77:96-109.

DOI 10.1016/j.agwat.2004.09.038

Li GW, Gao XH, Xiao NW, Xiao YF. 2019. Estimation of Soil Organic Matter Content Based on Variable Selection and Regression Methods by Vis-NIR Spectra. Acta Optica Sinica 1-18. (in Chinese).

DOI 10.3788/aos201939.0930002

Li LY, Chen Y, Xu TB, Liu R, Shi KF, Huang C. 2015. Super-resolution mapping of wetland inundation from remote sensing imagery based on integration of back-propagation neural network and genetic algorithm. Remote Sensing of Environment 164:142-154.

DOI 10.1016/j.rse.2015.04.009

Lindner C, Bromiley PA, Ionita MC, Cootes TF. 2015. Robust and Accurate Shape Model Matching Using Random Forest Regression-Voting. IEEE Transactions on Pattern Analysis and Machine Intelligence 37(9):1862-1874.

DOI 10.1109/tpami.2014.2382106

Maimaitiyiming M, Sagan V, Sidike P, Kwasniewski MT. 2019. Dual Activation Function-Based Extreme Learning Machine (ELM) for Estimating Grapevine Berry Yield and Quality. Remote Sensing. 11(7):740.

DOI 10.33390/rs11070740

Metternicht GI, Zinck JA. 2003. Remote sensing of soil salinity: potentials and constraints. Remote Sensing of Environment 85(1): 1-20.

DOI 10.1016/S0034-4257(02)00188-8

PeerJ reviewing PDF | (2019:10:42629:2:1:CHECK 1 Apr 2020) 
651 DOI 10.1046/j.0016-8025.2001.00808.x

652 Mutanga O, Adam E, Cho MA. 2012. High density biomass estimation for wetland

653

654

655

656

657

658

659

660

661

662

663

664

665

666

667

668

669

670

671

672

673

674

675

676

677

678

679

680

681

682

683

684

685

686

687

688

689

690

691

692

693

694 vegetation using WorldView-2 imagery and random forest regression algorithm. International Journal of Applied Earth Observation and Geoinformation 18(1):399-406.

DOI 10.1016/j.jag.2012.03.012

Nawar S, Buddenbaum H, Hill J, Kozak J, Mouazen AM. 2016. Estimating the soil clay content and organic matter by means of different calibration methods of vis-NIR diffuse reflectance spectroscopy. Soil \& Tillage Research 155:510-522.

DOI 10.1016/j.still.2015.07.021

Oliveira S, Oehler F, San-Miguel-Ayanz J, Camia A, Pereira JCM. 2012. Modeling spatial patterns of fire occurrence in Mediterranean Europe using Multiple Regression and Random Forest. Forest Ecology \& Management 275(4):117-129.

DOI 10.1016/j.foreco.2012.03.003

Pradhan B, Lee S. 2010. Regional landslide susceptibility analysis using back-propagation neural network model at Cameron Highland, Malaysia. Landslides.7(1):13-30.

DOI 10.1007/s10346-009-0183-2

Santos ICDL, Santos AD, Oumar Z, Soares MA, Silva JCC, Zanetti R, Zanuncio JC. 2019. Remote Sensing to Detect Nests of the Leaf-Cutting Ant Atta sexdens (Hymenoptera: Formicidae) in Teak Plantations. Remote Sensing 11(14):1641.

DOI 10.3390/rs11141641

Shataee S, Kalbi S, Fallah A, Pelz D. 2012. Forest attribute imputation using machine-learning methods and ASTER data: comparison of k-NN, SVR and random forest regression algorithms. International Journal of Remote Sensing 33(19):6254-6280.

DOI 10.1080/01431161.2012.682661

Sidike A, Zhao SH, Wen YM. 2014. Estimating soil salinity in Pingluo County of China using QuickBird data and soil reflectance spectra.International. Journal of Applied Earth Observation and Geoinformation 26: 156-175.

DOI 10.1016/j.jag.2013.06.002

Tavakkoli E, Fatehi F, Coventry S, Rengasamy P, Mcdonald GK. 2011. Additive effects of $\mathrm{Na}+$ and $\mathrm{Cl}$ - ions on barley growth under salinity stress. Journal of Experimental Botany 62:2189-2203.

DOI 10.1093/jxb/erq422

Wang HF, Chen YW, Zhang ZT, Chen HR, Li XW, Wang MX, Chai HY. 2019. Quantitatively estimating main soil water-soluble salt ions content based on Visible-near infrared wavelength selected using GC, SR and VIP. PeerJ 7:e6310.

DOI 10.7717/peerj.6310

Wang HF, Zhang ZT, Arnon K, Chen JY, Han WT. 2018. Hyperspectral estimation of desert soil organic matter content based on gray correlation-ridge regression model. Transactions of the Chinese Society of Agricultural Engineering 34:124-131.(in Chinese). 
695

696

697

698

699

700

701

702

703

704

705

706

707

708

709

710

711

712

713

714

715

716

717

718

719

720

721

722

723

724

725

726

727

728

729

730

731

732

733

734

735

736

737

738

DOI 10.11975/j.issn.1002-6819.2018.14.016

Wang JZ, Ding JL, Abulimiti A, Cai LH. Quantitative estimation of soil salinity by means of different modeling methods and visible-near infrared (VIS-NIR) spectroscopy, Ebinur Lake Wetland, Northwest China. Peer J 6:e4703

DOI 10.7717 /peerj.4703

Wang JZ, Ding JL, Yu DL, Ma XK, Zhang ZP, Ge XY, Teng DX, Li XH, Liang J, Lizaga I, Chen XY, Yuan L, Guo YH. 2019. Capability of Sentinel-2 MSI data for monitoring and mapping of soil salinity in dry and wet seasons in the Ebinur Lake region, Xinjiang, China. Geoderma 353:172-187.

DOI 10.1016/j.geoderma.2019.06.040

Wang LY, Fan H, Wang YK. 2019. Fine-Resolution Population Mapping from International Space Station Nighttime Photography and Multisource Social Sensing Data Based on Similarity Matching. Remote Sensing 11(16): 1900.

DOI 10.3390/rs1161900

Wang SJ, Chen YH, Wang MG, Zhao YF, Li J. 2019. Spa-based methods for the quantitative estimation of the soil salt content in saline-alkali land from field spectroscopy data: A Case Study from the Yellow River Irrigation Regions. Remote Sensing 11(8): 967.

DOI 10.3390/rs11080967

Wang XP, Zhang F, Ding JL, Kung HT, Latif A, Johnson VC. 2018. Estimation of soil salt content (SSC) in the Ebinur Lake Wetland National Nature Reserve (ELWNNR), Northwest China, based on a Bootstrap-BP neural network model and optimal spectral indices. Science of The Total Environment 615:918-930.

DOI 10.1016/j.scitotenv.2017.10.025

Wang XP, Zhang F, Kung HT, Johnson VC. 2018. New methods for improving the remote sensing estimation of soil organic matter content (SOMC) in the Ebinur Lake Wetland National Nature Reserve (ELWNNR) in northwest China. Remote Sensing of Environment 218:104-118.

DOI 10.1016/j.rse.2018.09.020

Weng YL, Gong P. 2006. A review on remote sensing Technique for salt-affected soils. Scientia Geographica Sinca. 26(3): 369-375. (in Chinese)

DOI 10.3969/j.issn.1000-0690.2006.03.019

Wold S, Martens H, Wold H. 1983. The Multivariate Calibration Problem in Chemistry Solved by the PLS Method, Lecture Notes in Mathematics. Matrix Pencils. Springer Berlin Heidelberg, 286-293.

DOI 10.1007/BFb0062108

Wu D, Zhou Z, Feng SJ, He Y. 2009. Uninformation Variable Elimination and Successive Projections Algorithm in Mid-Infrared Spectral Wavenumber Selection. International Congress on Image \& Signal Processing. IEEE.

DOI 10.1109/CISP.2009.5303610

Wu JW, Vincent B, Yang JZ, Bouarfa S, Vidal A. 2008. Remote Sensing Monitoring of Changes in Soil Salinity: A Case Study in Inner Mongolia, China. Sensors 8(11): 7035-7049.

DOI $10.3390 / \mathrm{s} 8117035$ 
739 Xu L, Wang Q. 2015. Retrieval of Soil Water Content in Saline Soils from Emitted Thermal Infrared Spectra Using Partial Linear Squares Regression. Remote Sensing 7:14646-14662.

742 DOI 10.3390/rs71114646

Yi XS, Lan AJ, Wen XM, Zhang Y, L Y. 2018. Monitoring of heavy metals in farmland soils based on ASD and GaiaSky-mini. Chinese Journal of Ecology 37(6): 1781-1788.

DOI 10.13292/j.1000-4890.201806.035

Yu H, Liu MY, Du BJ, Wang ZM, Hu LJ, Zhang B. 2018. Mapping Soil Salinity/Sodicity by using Landsat OLI Imagery and PLSR Algorithm over Semiarid West Jilin Province, China. Sensors 18(4): 1048.

DOI $10.3390 / \mathrm{s} 18041048$

Zeraatpisheh M, Ayoubi S, Jafari A, Tajik S, Finke P. 2019. Digital mapping of soil properties using multiple machine learning in a semi-arid region, central Iran. Geoderma.338:445-452.

DOI 10.1016/j.geoderma.2018.09.006

Zewdu S, Suryabhagavan KV, Balakrishnan M. 2017. Geo-spatial approach for soil salinity mapping in Sego Irrigation Farm, South Ethiopia. Journal of the Saudi Society of Agricultural Sciences 16(1):16-24.

DOI 10.1016/j.jssas.2014.12.003 
Figure 1

Location of the study area. A, B, C and D represent the distribution of the four study areas respectively.

A, B, C and D represent the distribution of the four study areas respectively.

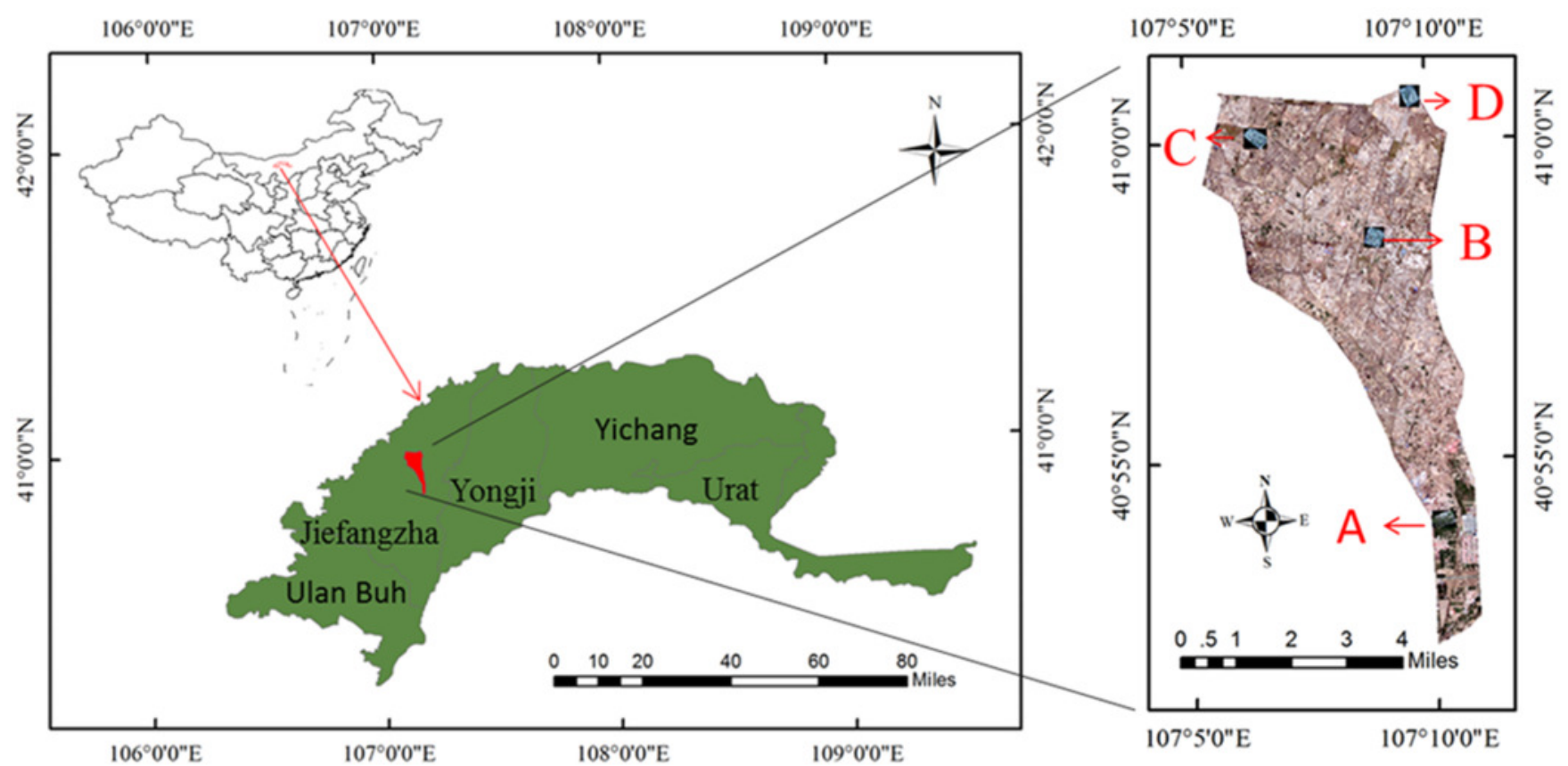


Figure 2

Location of the study area. A, B, C and D represent the distribution of the four study areas respectively.

$107^{\circ} 10^{\prime} 0^{\prime \prime} \mathrm{E}$

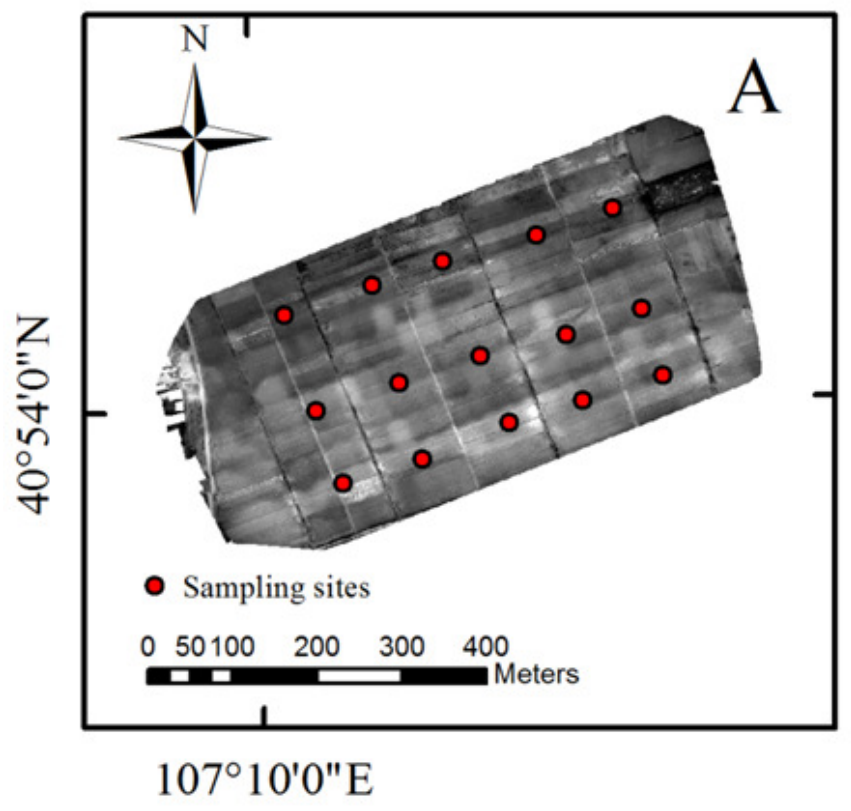

$107^{\circ} 6^{\prime} 30^{\prime \prime} \mathrm{E}$

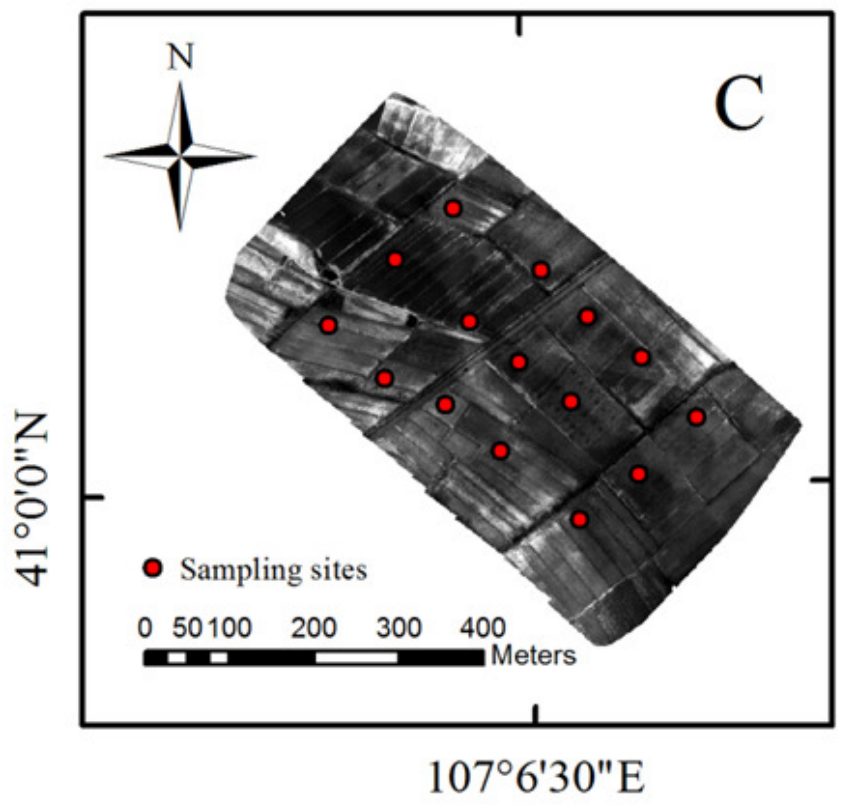

$107^{\circ} 9^{\prime} 0^{\prime \prime} \mathrm{E}$

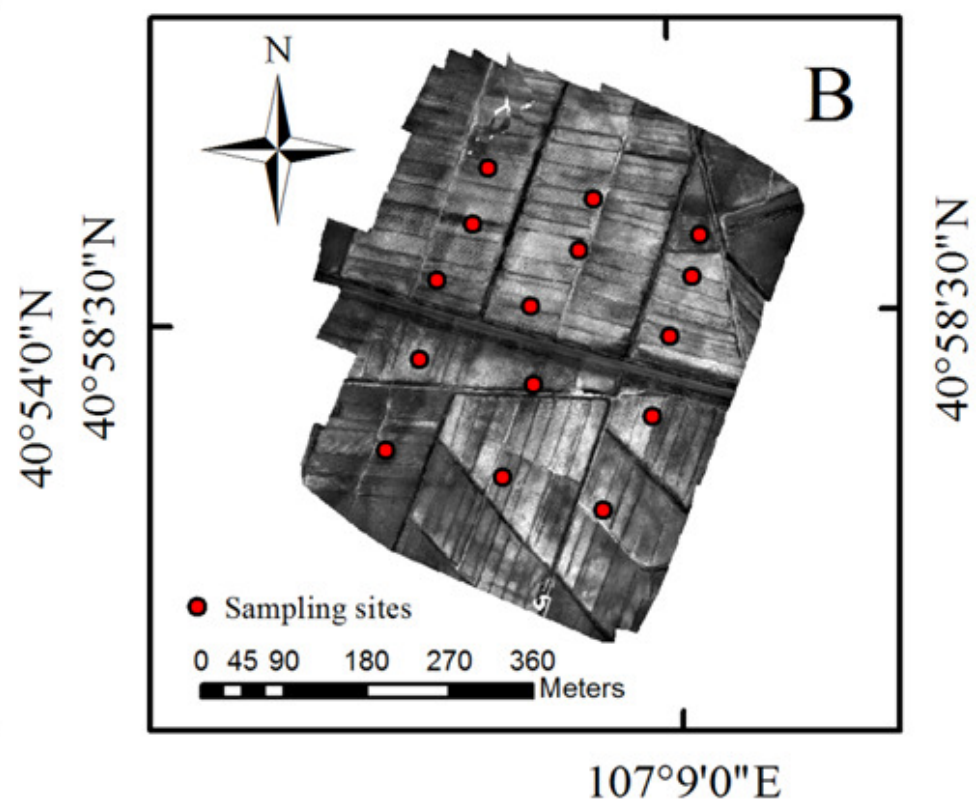

$107^{\circ} 9^{\prime} 30^{\prime \prime} \mathrm{E}$

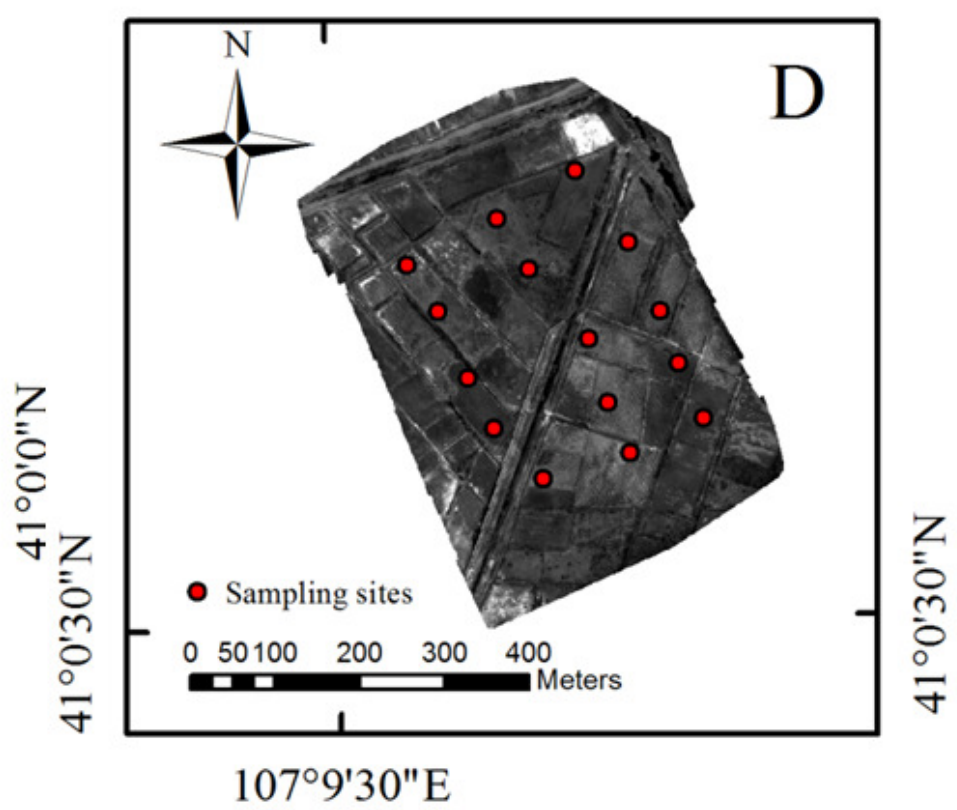




\section{Figure 3}

M600 unmanned aerial vehicle and Micro-MCA multispectral sensor.

(A)M600 unmanned aerial vehicle; (B) Micro -MCA multispectral sensor

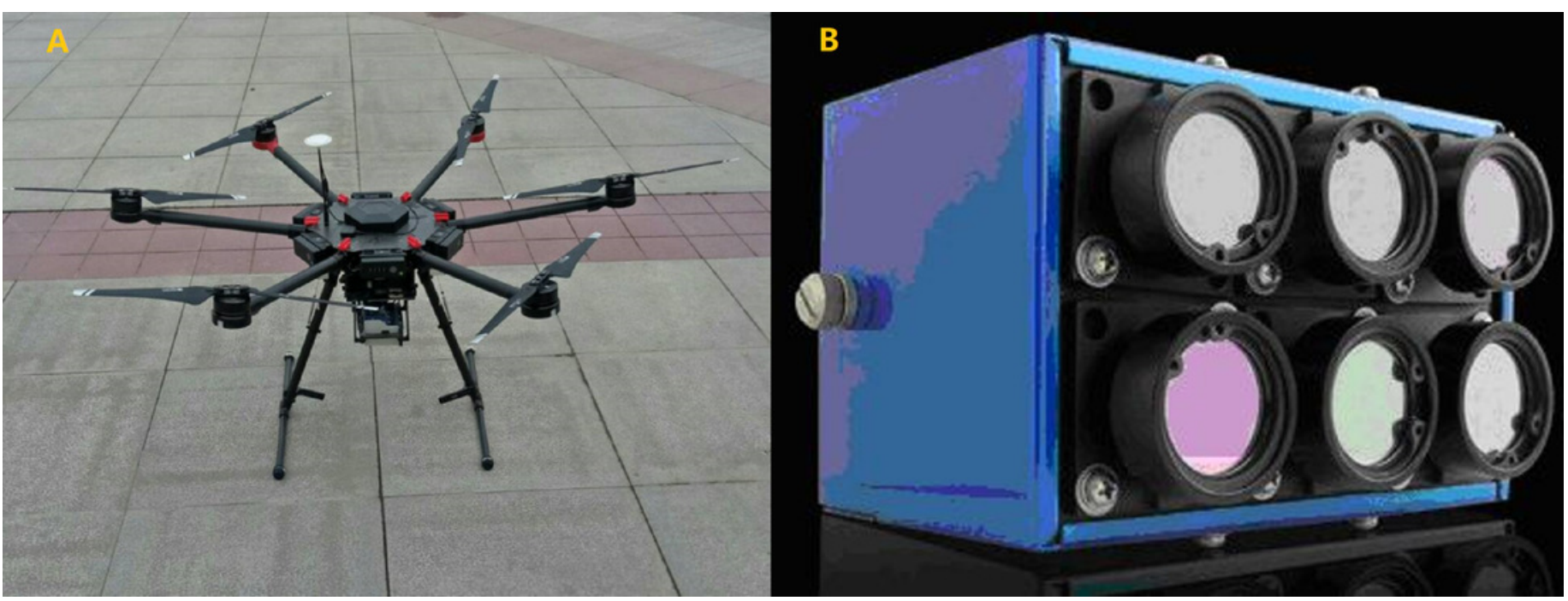


Figure 4

Method flow chart.

(A)Data preprocessing (B) modeling; and (C) analysis

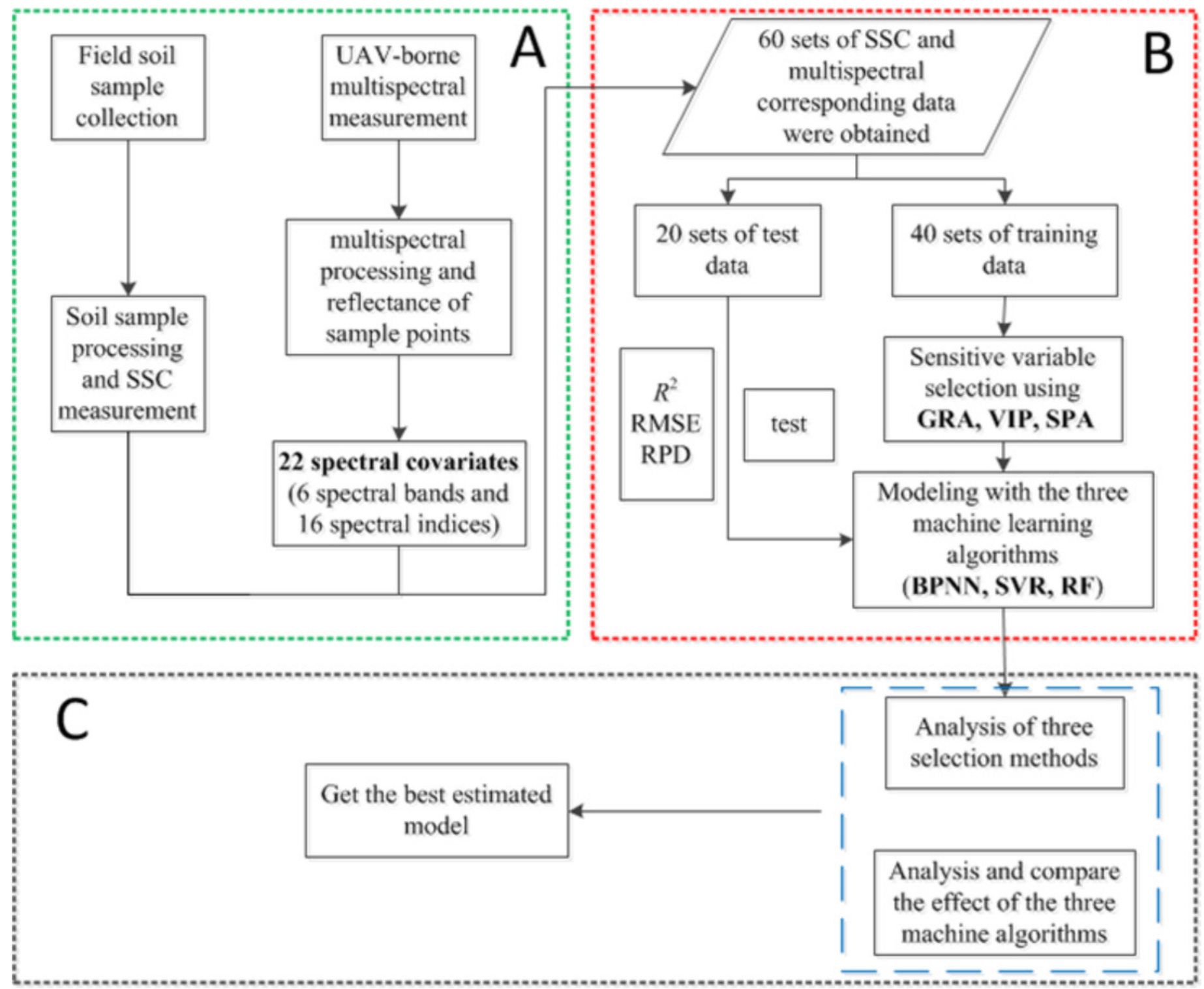


Figure 5

Violin plots showing the statistics of SSC for entire dataset, calibration dataset and validation dataset (\%).

S.D.: standard deviation.
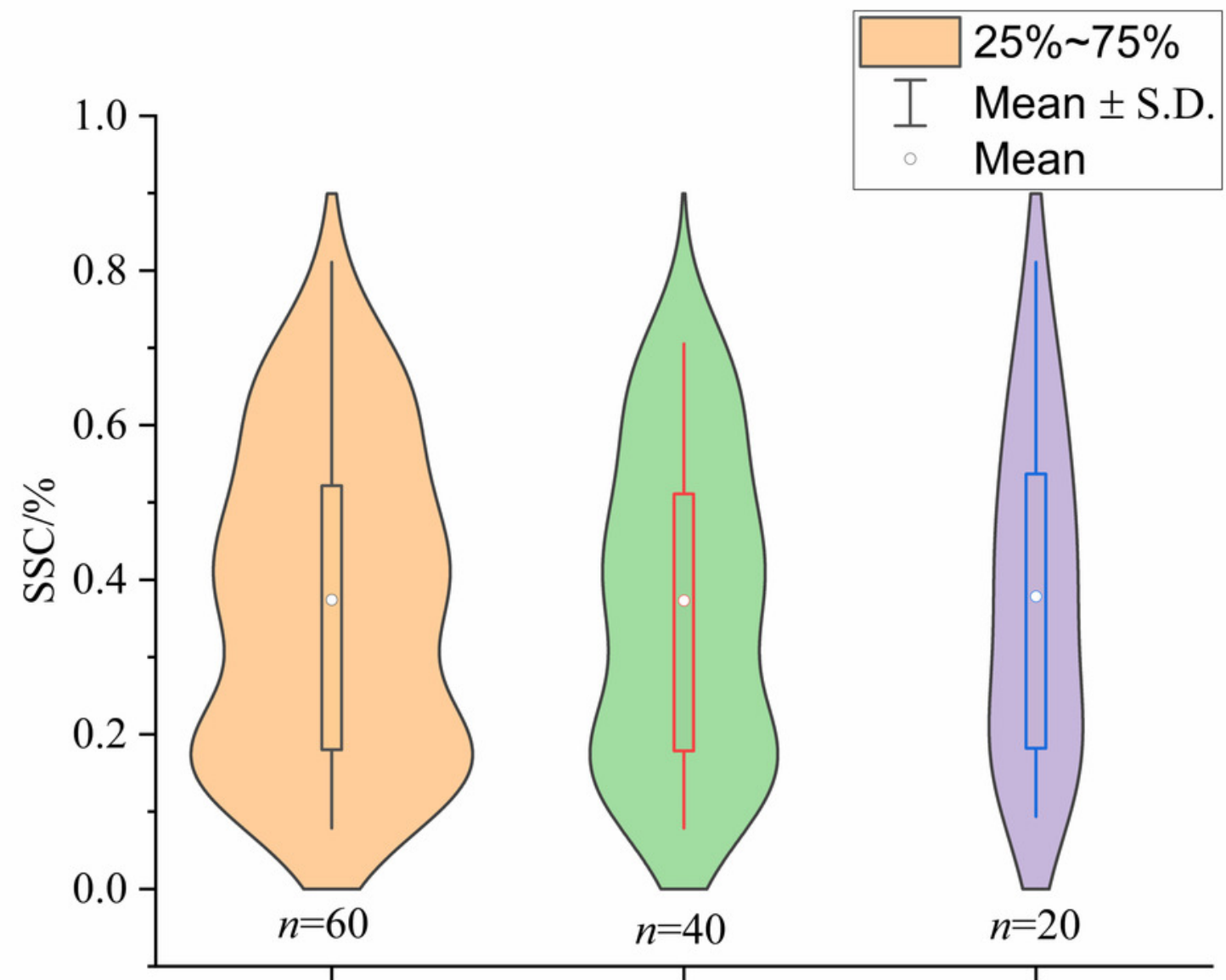

Entire dataset Calibration dataset Validation dataset

$\begin{array}{lll}\text { Mean }=0.369 & \text { Mean }=0.363 & \text { Mean }=0.382 \\ \text { S.D. }=0.198 & \text { S.D. }=0.194 & \text { S.D. }=0.205\end{array}$




\section{Figure 6}

The correlation coefficients of the measured SSC data and the three 2D indices for the two random spectral bands.

(A) RI; (B) DI ;(C) NDI.The color bar on the right side represents the color of Pearson's correlation coefficient (PCC) values. Red stands for positive correlation and blue for negative. The darker the color was, the larger the PCC value was.
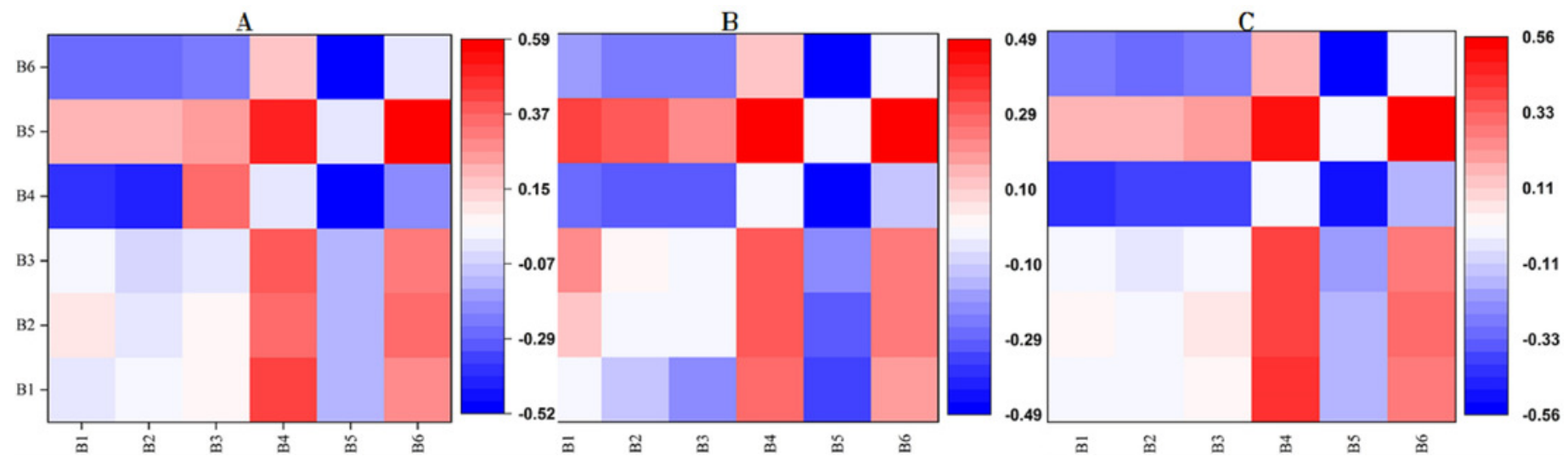
Figure 7

Gray correlation degree between the Variables and SSC

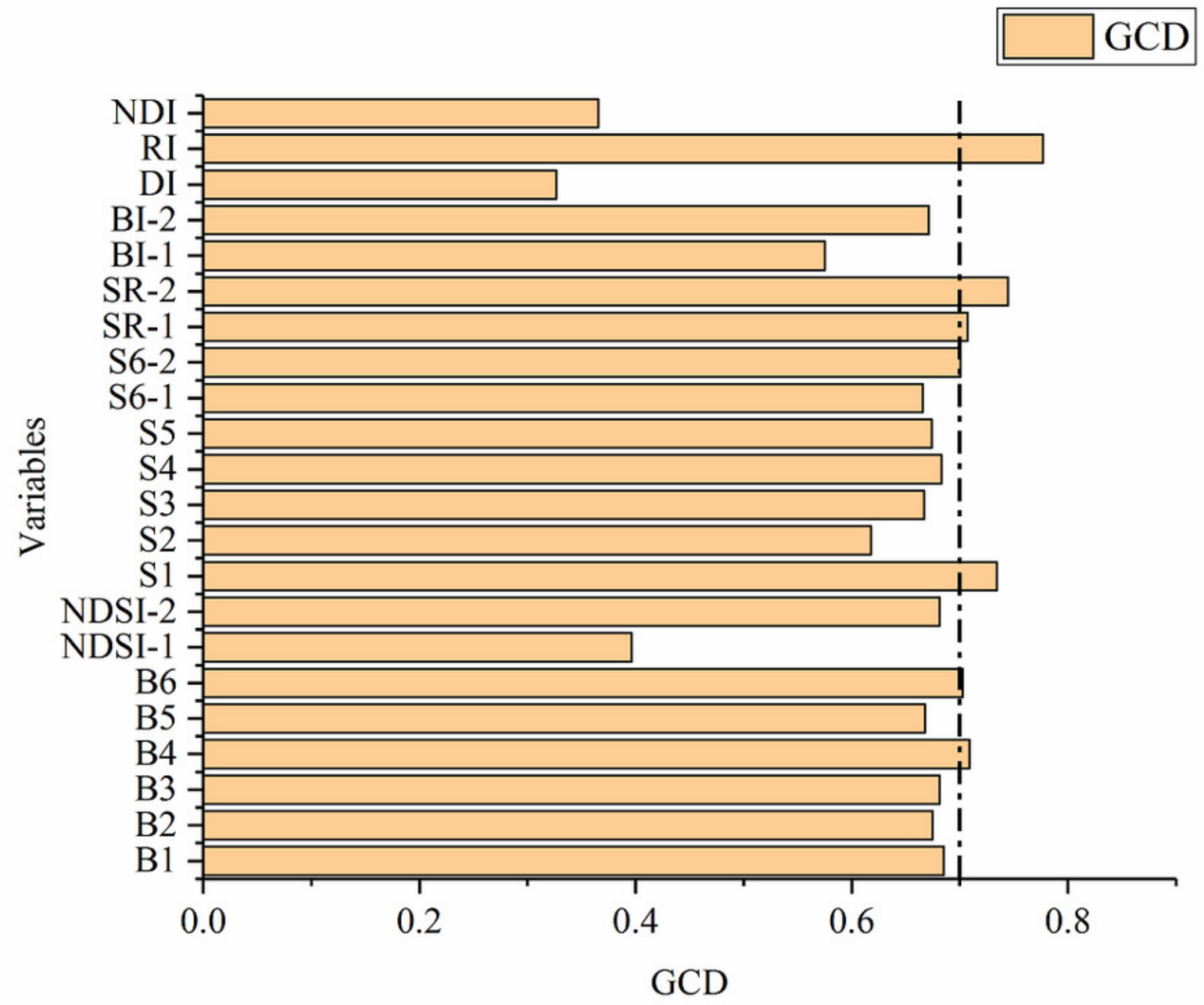


Figure 8

The selected Variables based on SPA

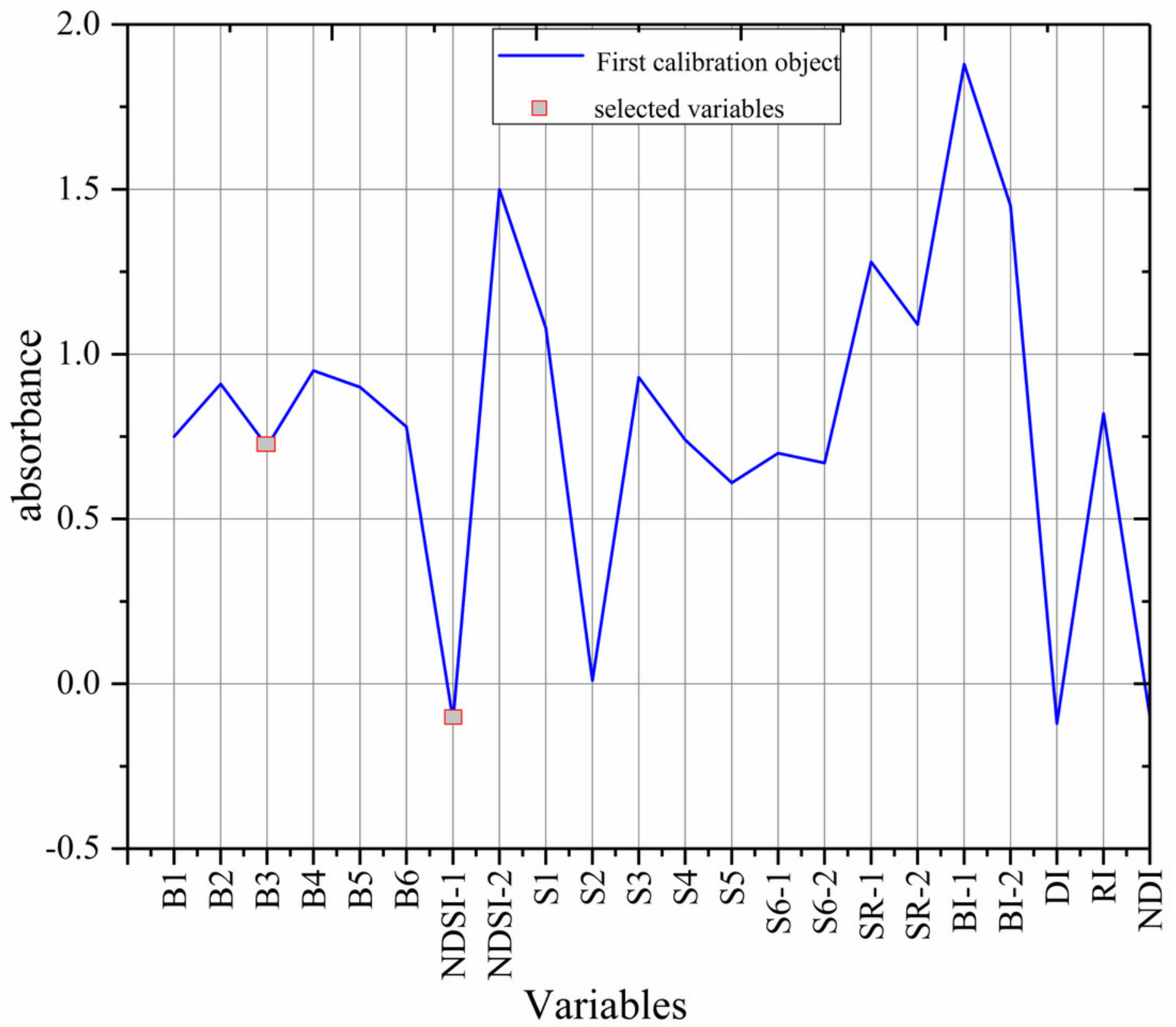


Figure 9

VIP score of Variables for SSC estimation

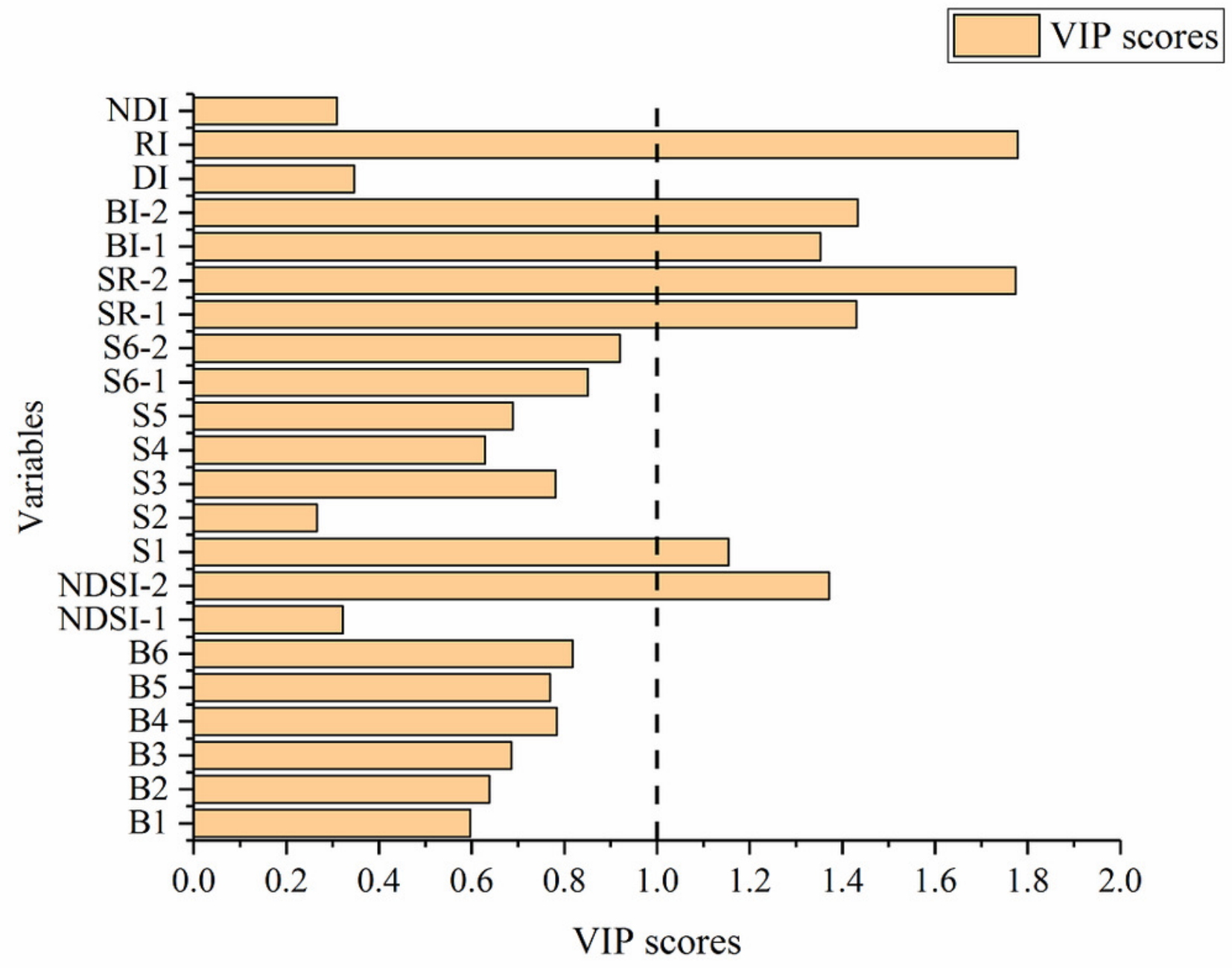


Figure 10

Prediction performance of the models.

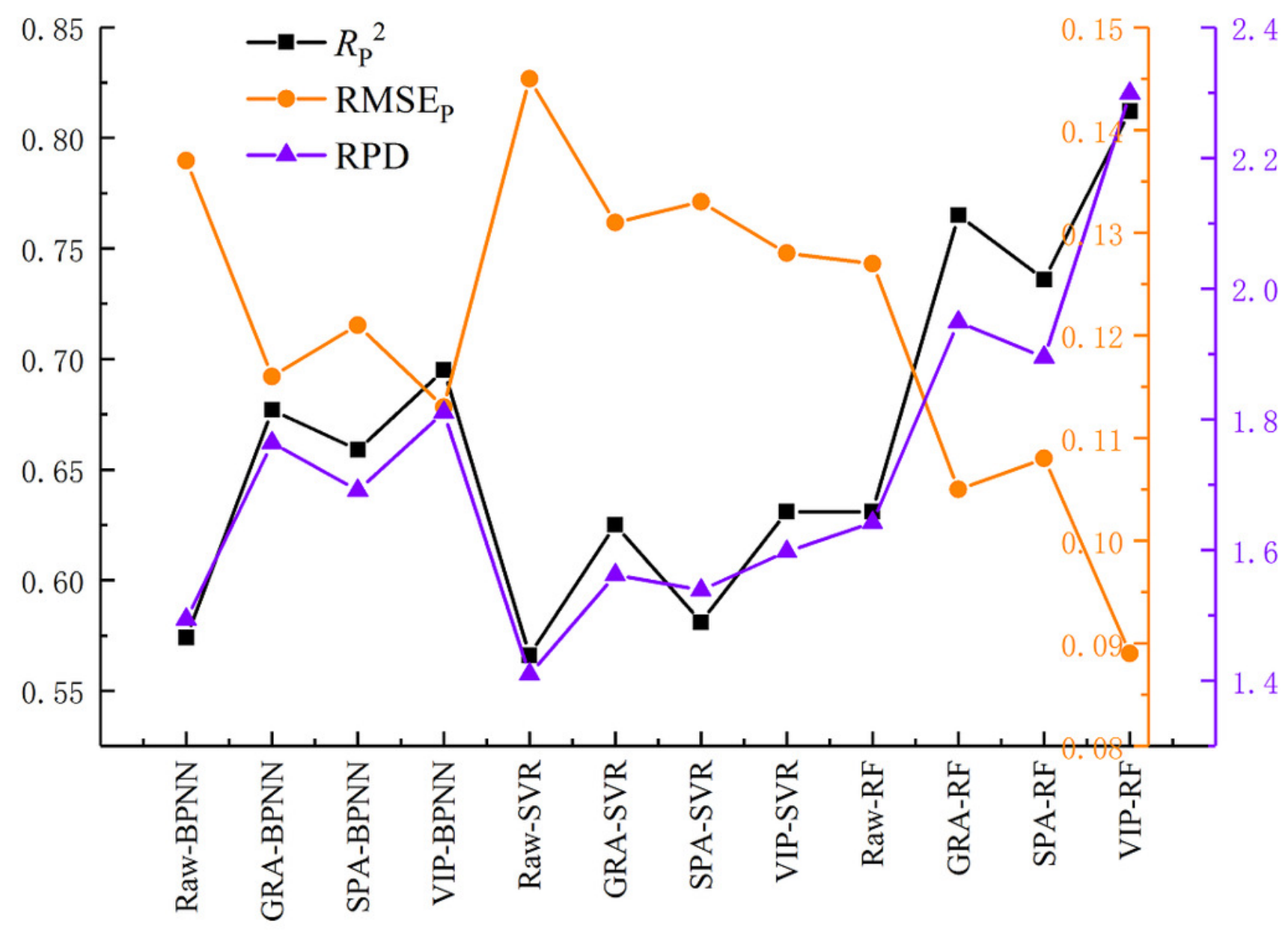


Figure 11

Comparison of the estimation results of the variable selection models.

(A) GRA-BPNN, (B) SPA-BPNN (C) VIP-BPNN, (D) GRA-SVR; (E) SPA-SVR; (F) VIP-SVR; (G) GRA-

RF; (H) SPA-RF; (I) VIP-RF.
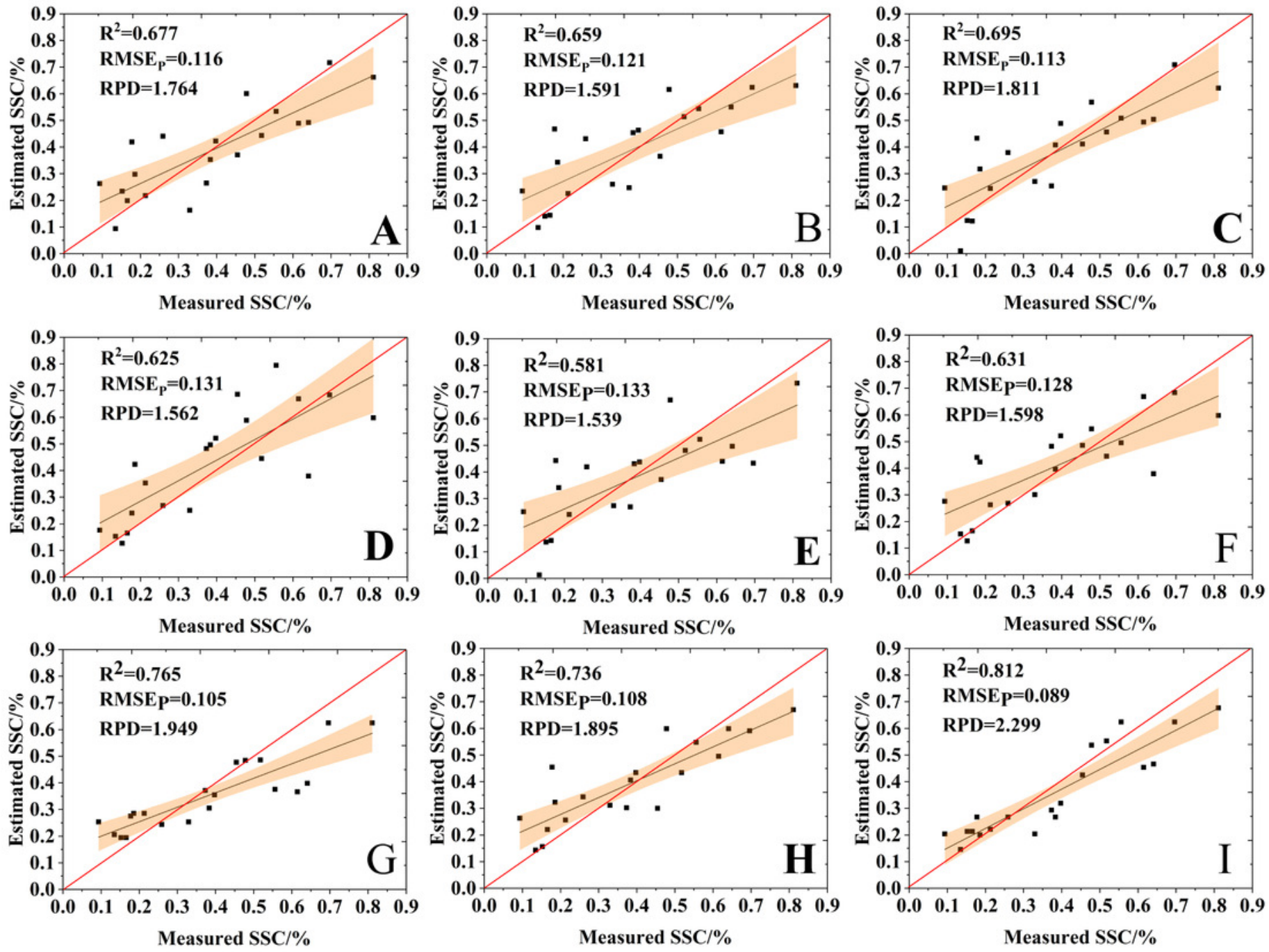


\section{Table 1 (on next page)}

MCA multispectral sensor parameters 


\begin{tabular}{cc}
\hline Parameter & Size \\
\hline Weight/g & 670 \\
Field angle & $38.26 \times 30.97$ \\
The highest pixel & $1280 \times 1024$ \\
& B1 $490(10-25)$ \\
& B2 $550(10-25)$ \\
Band and band width/nm & B3 $680(10-25)$ \\
& B4 $720(10-25)$ \\
& B5 $800(10-25)$ \\
\hline
\end{tabular}

1 


\section{Table 2 (on next page)}

Reference spectral indices.

$B, G, R, N I R 1$ and NIR2 are spectral reflectance at wavelengths of $490 \mathrm{~nm}, 550 \mathrm{~nm}, 680 \mathrm{~nm}$, $800 \mathrm{~nm}$ and $900 \mathrm{~nm}$, respectively. Bi and $B_{j}$ represent the reflectance values from random spectral bands available from the multispectral sensor. 


\begin{tabular}{ccc}
\hline Spectral Index & Formula & Full Name \\
\hline S1 & $B / R$ & Salinity Index 1 \\
S2 & $(B-R) /(B+R)$ & Salinity Index 2 \\
S3 & $(G \times R) / B$ & Salinity Index 3 \\
S4 & $(B \times R)^{0.5}$ & Salinity Index 4 \\
S5 & $(B \times R) / G$ & Salinity Index 5 \\
S6-1 & $(R \times N I R 1) / G$ & Salinity Index 6-1 \\
S6-2 & $(R \times N I R 2) / G$ & Salinity Index 6-2 \\
SR-1 & $N I R 1 / R$ & Simple Ratio Index 1 \\
SR-2 & SiR2/R & Bimple Ratio Index 2 \\
BI-1 & $\left(R^{2}+N I R 1^{2}\right)^{0.5}$ & Brightness Index 1 \\
BI-2 & $\left(R^{2}+N I R 2^{2}\right)^{0.5}$ & Brightness Index 2 \\
NDSI-1 & $(R-N I R 1) /(R+N I R 1)$ & Normalized Difference Salinity Index 1 \\
NDSI-2 & $(R-N I R 2) /(R+N I R 2)$ & Normalized Difference Salinity Index 2 \\
DI & $B_{i}-B_{j}$ & Difference Index \\
RI & $B_{i} / B_{j}$ & Ratio index \\
NDI & $\left(B_{i}-B_{j}\right) /\left(B_{i} \pm B_{j}\right)$ & Normalization index \\
\hline
\end{tabular}




\section{Table 3(on next page)}

Summary statistics of soil salinity sampling points 


\begin{tabular}{ccccccc}
\hline Data Set & $\begin{array}{c}\text { None salinization } \\
(<0.2 \%)\end{array}$ & $\begin{array}{c}\text { Mild salinization } \\
(0.2 \% \sim 0.5 \%)\end{array}$ & $\begin{array}{c}\text { Severe salinization } \\
(0.5 \% \sim 1.0 \%)\end{array}$ & Min/\% & Max/\% & CV \\
\hline Entire dataset $\mathrm{n}=60$ & 20 & 24 & 16 & 0.08 & 0.81 & 0.54 \\
Calibration $(\mathrm{n}=40)$ & 14 & 16 & 10 & 0.08 & 0.81 & 0.54 \\
Validation $(\mathrm{n}=20)$ & 6 & 8 & 6 & 0.09 & 0.71 & 0.57 \\
\hline
\end{tabular}

1 
Table 4 (on next page)

The relationship between SSC and spectral indices.

$* \mathrm{p} \square 0.05 ; * * \mathrm{p} \square 0.01$ 
1

\begin{tabular}{cccc}
\hline Spectral index & $|R|$ & Spectral index & $|R|$ \\
\hline S1 & $0.36^{* *}$ & SR-2 & $0.30^{*}$ \\
S2 & $0.26^{*}$ & BI-1 & $0.71^{* *}$ \\
S3 & $0.59^{* *}$ & BI-2 & 0.21 \\
S4 & $0.66^{* *}$ & NDSI-1 & 0.19 \\
S5 & $0.43^{* *}$ & NDSI-2 & $0.72^{* *}$ \\
S6-1 & $0.71^{* *}$ & DI & $0.49^{* *}$ \\
S6-2 & $0.27^{*}$ & RI & $0.59^{* *}$ \\
SR-1 & 0.13 & NDI & $0.55^{* *}$ \\
\hline
\end{tabular}

2 
Table 5 (on next page)

The details on model parameters. 


\begin{tabular}{lccccc}
\hline & BPNN & \multicolumn{2}{c}{ SVR } & \multicolumn{2}{c}{ RF } \\
\cline { 2 - 6 } & size & $C$ & $g$ & ntree & mtry \\
\hline Raw-BPNN & 5 & - & - & - & - \\
GRA-BPNN & 3 & - & - & - & - \\
SPA-BPNN & 2 & - & - & - & - \\
VIP-BPNN & 3 & - & 0.01 & - & - \\
Raw-SVR & - & 1000 & 0.01 & - & - \\
GRA-SVR & - & 100 & 0.001 & - & - \\
SPA-SVR & - & 100 & 0.01 & - & - \\
VIP-SVR & - & 1000 & - & 500 & 3 \\
Raw-RF & - & - & - & 500 & 3 \\
GRA-RF & - & - & - & 500 & 3 \\
SPA-RF & - & - & - & 500 & 2 \\
VIP-RF & - & - & &
\end{tabular}

1 


\section{Table 6(on next page)}

Comparisons of different machine learning models based on different selection methods.

Note: "Raw", all variables; $R_{c}^{2} \square$ determination coefficient of calibration; $\mathrm{RMSE}_{\mathrm{c}}$, root mean squared error of calibration $\square R_{\mathrm{p}}{ }^{2} \square$ determination coefficient of validation $\square \mathrm{RMSE} \mathrm{E}_{\mathrm{p}} \square$ root mean squared error of validation $\square R P D \square$ ratio of performance to deviation. 


\begin{tabular}{cccccc}
\hline Acronym & $R_{c}{ }^{2}$ & RMSE $_{\mathrm{C}}$ & $R_{P}{ }^{2}$ & RMSE & RPD \\
\hline Raw-BPNN & 0.599 & 0.135 & 0.574 & 0.137 & 0.116 \\
GRA-BPNN & 0.661 & 0.116 & 0.677 & 0.121 & 1.794 \\
SPA-BPNN & 0.643 & 0.116 & 0.659 & 0.113 & 0.145 \\
VIP-BPNN & 0.675 & 0.118 & 0.695 & 0.131 \\
Raw-SVR & 0.533 & 0.136 & 0.666 & 0.133 & 1.811 \\
GRA-SVR & 0.645 & 0.120 & 0.581 & 0.128 & 1.410 \\
SPA-SVR & 0.582 & 0.126 & 0.631 & 0.127 & 1.539 \\
VIP-SVR & 0.643 & 0.115 & 0.631 & 0.105 & 1.598 \\
Raw-RF & 0.650 & 0.115 & 0.765 & 0.108 & 1.642 \\
GRA-RF & 0.768 & 0.099 & 0.736 & 0.089 \\
SPA-RF & 0.747 & 0.098 & 0.812 & 1.949 \\
VIP-RF & 0.835 & 0.085 & & 2.299 \\
\hline
\end{tabular}

1 